\title{
Tribo-corrosion of coatings: a review
}

\author{
Robert J K Wood \\ University of Southampton, SO17 1BJ, UK \\ Received 16 May 2007 \\ Published 30 August 2007 \\ Online at stacks.iop.org/JPhysD/40/5502
}

Surface Engineering and Tribology Group, School of Engineering Sciences, Highfield,

\begin{abstract}
This paper reviews the available literature relating to the emerging research into the performance of coatings under combined wear and corrosion conditions. Understanding how coatings perform under these tribo-corrosion conditions is essential if the service life of equipment is to be predicted and to allow service life to be extended. Therefore, the tribo-corrosion performance of coatings deposited by a variety of techniques is discussed and the main mechanisms associated with their degradation under combined wear and corrosion highlighted. Coating composition, microstructure, defect level, adhesion, cohesion and substrate properties are seen as some of the critical elements in coating performance when subjected to tribo-corrosion contacts. The importance of post-coating deposition treatments such as laser resurfacing and sealing are also discussed. Interactions between wear and corrosion mechanisms are identified along with some models and mapping techniques that aim to inform coating selection and predict performance. Recent investigations into mono-layer as well as multilayered and functionally graded coatings are reviewed as candidates for wear-corrosion resistant surfaces. The review reveals the need for a more considered approach to tribo-corrosion testing and the way in which the results are analysed and presented. For example, the test conditions should be appropriate to the coating system under test; the level of in situ instrumentation deployed and the post-test analysis of in situ electrochemical data should be carefully selected as well as details given of the composition of any surface tribofilms formed and the identification of the degradation mechanisms.
\end{abstract}

(Some figures in this article are in colour only in the electronic version)

\section{Introduction and definitions}

\subsection{Background and definition of tribo-corrosion}

The need to select or design new surfaces for future equipment as well as minimize the operating costs and extend the life of existing machinery has led to demands for a much better understanding of surface degradation processess particularly when tribological components are operating in corrosive environments. This has given rise to the active research area of tribo-corrosion which seeks to address the concerns above and understand the surface degradation mechanisms when mechanical wear and chemical/electrochemical processes interact with each other.

Tribo-corrosion involves the interaction between mechanical wear processes and electrochemical and/or chemical corrosion processes and leads to a material loss rate that is a summation of these effects, as shown below in equation (1):

$$
\begin{aligned}
& \text { Wear-corrosion }=\text { mechanical wear processes } \\
& \quad+\text { electrochemical (and/or chemical) response. }
\end{aligned}
$$

The subject started to be researched in the late 1980s and has now emerged as an active research area as advanced experimental techniques have been developed to yield substantial insight into the complex processes present in tribo-corrosion contacts. The development of in situ electrochemical techniques and post-test analysis techniques for surface film examination for example are powerful tools that can be deployed in tribo-corrosion experimental programmes. The subject, therefore, includes the interaction of corrosion and erosion (solids, droplets or cavitation bubbles), abrasion, adhesion, fretting and fatigue wear 
processes. For example, during friction the adhesive dissipation of energy is often influenced by chemical effects, Fischer and Mischler [1].

\subsection{Industrial and medical relevance}

Tribo-corrosion is encountered in many technological areas where it causes damage to human joints, slurry handling equipment and machines and can compromise safe operation and in the case of biotribocorrosion of prosthesis and restorative dentistry tribo-corrosion has implications for human health and quality of life. However, the chemomechanical mechanisms of tribo-corrosion are not well understood and are extremely complex as they involve the properties of contacting material surfaces or coatings, the mechanics of the contact and the corrosion conditions. Understanding is further hampered by the experimental difficulty in characterizing surface phenomena occurring within the tribo-contacts. A multitude of reactions probably occur simultaneously within the contact and the quantity of reaction products is likely to be very small, making their detection and analysis difficult. In addition, metastable phases could be generated within the contact but these are subsequently transformed into stable reaction products outside of the contact or have time dependent transformations.

Tribo-corrosion is often linked to the synergy resulting from the coupling of mechanical and environmental effects. This synergism or antagonism results in material degradation that is often much larger or smaller than would be expected from a simple summing of the mechanical and environmental effects.

On the positive side, tribo-corrosion phenomena can be used as a manufacturing process such as in chemicalmechanical polishing of silicon wafers. The coupling of mechanical and environmental effects can also create surfaces of specific reaction layers on materials which could inhibit corrosion and/or wear. Examples of this are self-lubricating and/or self-healing surface layers as mentioned by Celis and Ponthiaux [2].

Tribo-corrosion degradation affects components in numerous industries such as mining, automotive, food, nuclear, offshore, marine and biomedical just to name a few. These industries expend the equivalent of millions of pounds every year to repair damage, typically in ignorance that it has been caused by tribo-corrosion processes. Typical examples of this kind of material removal are erosion-corrosion damage to pumps, impellers, propellers, valves, heat exchanger tubes and other fluid handling equipment. The performance data and models published in the open literature aspire to allow informed surface selection for combined wear and corrosion resistance, but this information is vulnerable as few systematic test programmes are reported and many reports are incomplete. Therefore, there is little basic understanding of how even the most popular surfaces used in machinery perform when exposed to corrosive conditions which may often include temperature fluctuations. The transitions from relatively benign surface loss rates to unacceptable loss rates are not defined. Hence, identical machines often suffer from vastly different surface damage rates due to only subtle differences in the conditions of operation or for example in countries with different climates.

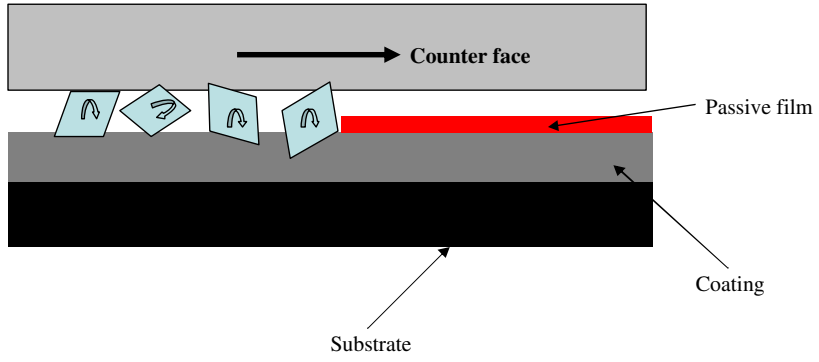

Figure 1. Schematic showing depassivation of a passivating coated surface by three body rolling abrasion induced by relative motion between the coated surface and a counter face.

\subsection{Interfacial aspects and the role of oxides}

Stainless steels rely on a $1-10 \mathrm{~nm}$ thick surface oxide passive film for their protection from aggressive and corrosive environments. This oxide film forms instantaneously when oxygen is available in the environment but abrasion can lead to the local rupture or complete removal of these films. This can lead to areas of the substrate being exposed to the aggressive environment and unless repassivation (repair or self-healing) mechanisms reform the passive film, accelerated anodic dissolution will occur within these sites. The response of some of these passivating surfaces relates to the rate of depassivation due to stripping (or damage) to the protective passive (e.g. oxide) film and the rate of repassivation (healing of the passive film). Clearly if the former is higher than the latter, then nascent bulk material is exposed to the corrosive environment and high dissolution rates may result. Therefore, the wear-corrosion performance of metallic coatings relates not only to the integrity of the coating and whether the substrate is exposed to the environment but also to the passive film state on the coating surface. Figure 1 illustrates passive film and coating removal that can accelerate wear-corrosion under three body rolling abrasion while figure 2 shows how an impinging solid particle can damage passive films of ductile metallic surfaces and how this is dependent on impact angle. However, there is no direct relationship between surfaces that readily passivate and are thought to be corrosion resistant and lower loss rates under wear-corrosion. This lack of understanding has badly hampered improving the performance of machines in aggressive environments.

The presence of oxides could also affect the level of plastic deformation and the depth of surface penetration made by the harder asperities into the softer counter body surface. The presence of well-adhered oxide surface films or loosely adhered layers of corrosion products and the ability to reform these films and layers is also critical in many engineering applications where control of friction and wear is important. Friction forces for certain materials can be modelled by considering summing the forces associated with adhesive and deformation processes. Adhesive forces are often related to the shear strength of junctions made between contacting asperities of surfaces in contact with each other but in relative motion. The presence of oxide films on these asperities could clearly influence the resulting forces opposing motion and surface temperatures generated during contact. 


\subsection{Additional factors associated with coatings}

Understanding the tribo-corrosion of coatings is far harder compared with many monolithic surfaces as the coating processes used can unintentionally degrade the coating microstructure by adding significant porosity and pockets of oxides into the coating and the coating process can also affect the substrate properties. Also remnants from the precoating substrate treatments (such as shot or grit blasting) can be embedded into the surface and then subsequently coated, thereby degrading the adhesive properties of the coating/substrate interface or the coating cohesion by weakening the bonding between any inclusions and the matrix. These add to the already complex interactions that can occur in wearing contacts as shown in figure 3 , which include electrochemical activity of the wear debris with the contacting

(1)

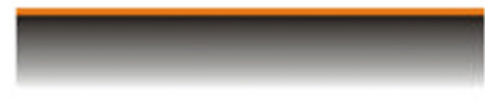

(2)

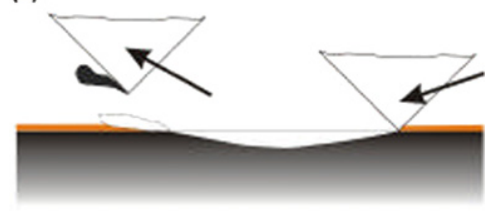

(3)

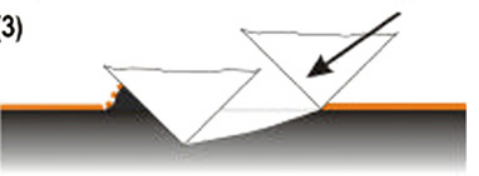

(4)

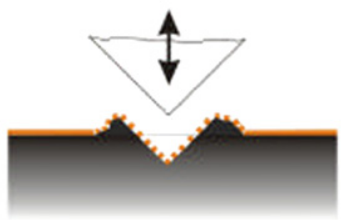

Figure 2. Removal or fracture of passive films dependent on erodent impingement angle. (1) Initial undamaged passivated surface, (2) low angle impingement results in cutting and removal of passive film and substrate material, (3) intermediate angle of impingement results in some cutting and removal of passive film plus some plastic cratering and fracture of the passive film and (4) impingement normal to the surface leads to plastic cratering/lipping and fracture of the passive film. surfaces and material transfer between contacting surfaces which can radically change the composition of the surface and the wear and corrosion resistance of that surface.

Complex microstructures with multiple phases of coatings can lead to micro-galvanic activity and selective phase corrosion. Examples of such surfaces include composites or surfaces that undergo tribologically induced compositional changes. For instance the presence of carbides in a metallic surface, typically formed for improved wear resistance, establishes a micro-corrosion cell as the carbide is likely to be cathodic with respect to the surrounding metallic matrix. This can result in preferential anodic dissolution of the metallic matrix close to or at the matrix/carbide interface and thereby accelerate carbide removal from surfaces and reduce the antiwear properties of the surface, [3].

\subsection{Basic phenomena to consider}

Tribo-corrosion includes the interaction of corrosion with

- solid particle erosion,

- abrasion,

- cavitation erosion,

- fretting,

- biological solutions,

- sliding wear and tribo-oxidation.

These interactions are represented schematically in figure 4 .

Cost reduction considerations favour replacing expensive solid alloy components with coatings on inexpensive carbon steel substrates. The relatively cheap option of organic coatings tends to perform poorly under high energy solid particle impingement but have a use as corrosion barrier coatings within low energy flow components, see Percy [4], whereas ceramic materials are usually too expensive to use, except in particularly critical applications. Sprayed metallic coatings are a relatively unexplored possibility for this duty. The most likely metallic coating materials for thermal spray systems, on cost grounds, are aluminium, copper, nickel and zinc, their alloys and possibly composite materials based on them. For more aggressive environments Co-based (e.g. sprayed and fused stellite) or Ni based (Inconel) coatings are preferred as they provide enhanced performance against wear-corrosion. For highly aggressive (very energetic flows) $\mathrm{WC}-\mathrm{CoCr}$ or $\mathrm{WC}-\mathrm{NiCr}$ cermets are used either in sintered form or thermally sprayed by detonation type or high velocity oxy-fuel (HVOF) thermal spray guns [5-7].

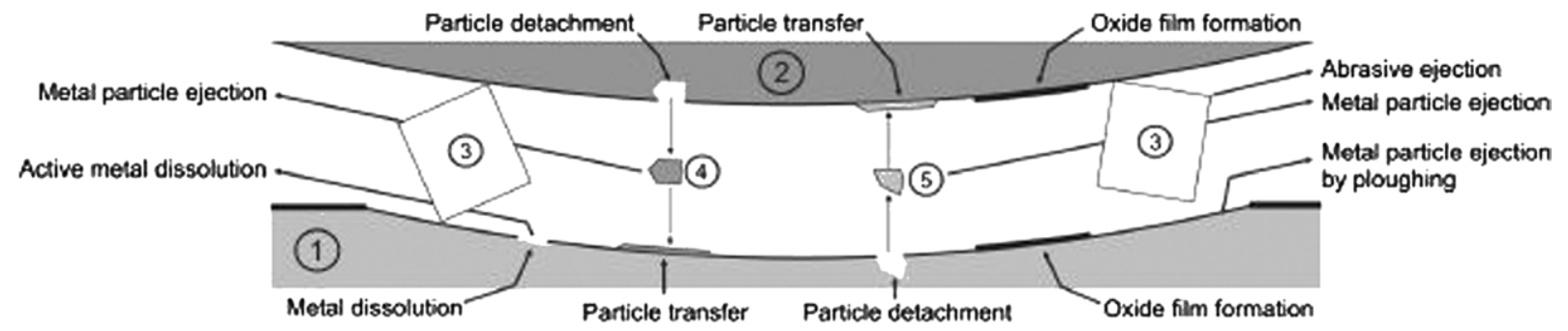

Figure 3. Schematic illustration of the tribo-corrosion contact involving two metallic samples first body and second body and abrasive particles (third body). Wear particles originating from the first and second bodies (4 and 5) form additional contact components. The corresponding material fluxes are also indicated. 


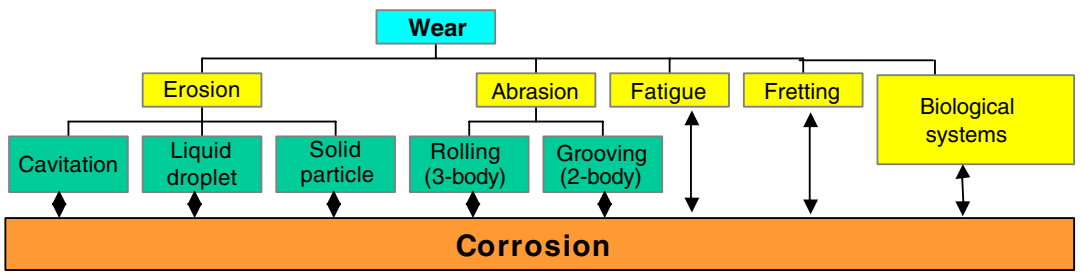

Figure 4. Possible interactions between corrosion and the various wear mechanisms.

To achieve long term corrosion resistance, it is important to understand the galvanic interaction between the metallic coating and the substrates. For example, anodic coatings to carbon steel will protect the steel galvanically in electrolytes. For cathodic coatings where defects in the coating occur (i.e. porosity), exposed steel is likely to form the anode of an electrochemical cell and rapidly corrode, adding to wearcorrosion attack and spallation of the coating. It would be a condition for using cathodic coatings that either the coating is defect free or that a sealant is used if substrate protection is to be achieved. Coating interfaces which can be coating/coating, coating/substrate or coating/interlayer/substrate are vulnerable parts of any coating system. They can distort subsurface stress fields induced by tribo-contacts and cause spallation of the coating by lowering the interfacial adhesion of the coating and promote interfacial crack propagation. As a way of summarizing the above introductory comments, and to introduce the breadth of this research field, the possible surface responses to a variety of contact conditions are given in table 1 .

The deposition of coatings typically involves multiple steps such as in PVD deposition of thin $\mathrm{Cr}_{3} \mathrm{C}_{2}$ films on stainless steels. The process starts with chromium ion etching of the substrate to enhance epitaxial film growth and coating adhesion to the substrate. This is followed by the deposition of a $\mathrm{CrN}$ base layer to further enhance adhesion and finally the deposition of the top $\mathrm{Cr}_{3} \mathrm{C}_{2}$ coating [8]. PVD multilayered coatings are even more complex and vary the composition of layers to maximize $\mathrm{E} / \mathrm{H}$ (elastic modulus/hardness) ratios. Thus, this can give non-linear relationships between tribocorrosion rates and coating depths.

1.5.1. Fretting. Fretting damage, such as suffered by gas turbine blade roots and by replacement joints in humans, is associated with wear-corrosion processes. Barril et al [9] found only fretting regimes involving slip led to measurable wear and to an enhancement of the anodic current. Previously developed tribo-corrosion models for passivating metals were found to describe the effect of normal force and displacement amplitude on the anodic current. For a smooth hard indenter sliding against a soft passive metal the current can be given by $I_{r}$ :

$$
I_{r}=k\left(\frac{1}{\lambda}\right) v_{\mathrm{s}}\left(\frac{F_{\mathrm{n}}}{H}\right) Q_{\mathrm{p}},
$$

where $k$ is the probability factor, $\lambda$ is the length of the sliding direction, $v_{\mathrm{s}}$ is the sliding velocity, $F_{\mathrm{n}}$ is the normal force, $H$ is the metal hardness and $Q_{\mathrm{p}}$ the passivation charge density.

The fretting corrosion behaviour of a Ti6Al4V alloy in contact with an alumina ball has been investigated by Barril et al [10] in a $0.9 \%$ sodium chloride solution. The tests were carried out using a fretting test rig equipped with an
Table 1. Summary of tribological effects on corrosion/surface phenomena.

\begin{tabular}{|c|c|}
\hline Contact conditions & Response \\
\hline $\begin{array}{l}\text { Contact load } \\
\text { and geometry }\end{array}$ & $\begin{array}{l}\text { 1. Contact stress (surface and } \\
\text { subsurface) and contact area } \\
\text { 2. Elastic or elastic-plastic or } \\
\text { fully plastic surface and subsurface } \\
\text { response } \\
\text { 3. Surface deflection (elastic or } \\
\text { permanent) }\end{array}$ \\
\hline $\begin{array}{l}\text { Relative motion } \\
\text { under load } \\
\text { (causing wear) } \\
\text { in a corrosive } \\
\text { environment }\end{array}$ & $\begin{array}{l}\text { 1. Induces depassivation } \\
\text { of passive surface } \\
\text { and primary ion release } \\
\text { 2. Effects } E_{\text {corr }} \text { (mixed potential } \\
\text { of worn and unworn surfaces). } \\
\text { 3. Induces surface and near } \\
\text { surface phase transformations } \\
\text { 4. Effects repassivation kinetics } \\
\text { 5. Increases local mass transport } \\
\text { 6. Increases contact temperature } \\
\text { 7. Increases roughness and } \\
\text { thus area of surfaces in contact } \\
\text { 8. Changes surface layer compositions } \\
\text { 9. Induces a mechanically mixed } \\
\text { layer on the surfaces of the } \\
\text { tribocouples including } \\
\text { embedded wear debris. } \\
\text { 10. Establishes a galvanic } \\
\text { process between worn area } \\
\text { and unworn area as a result of (2). } \\
\text { 11. Induces surface strain hardening } \\
\text { 12. Affects shear strength of } \\
\text { asperity/asperity junctions } \\
\text { between tribocouples and thus } \\
\text { adhesive contributions } \\
\text { to the friction force. }\end{array}$ \\
\hline $\begin{array}{l}\text { Varying the applied } \\
\text { load of dynamic } \\
\text { contacts }\end{array}$ & $\begin{array}{l}\text { 1. Free corrosion potential [8] } \\
\text { 2. Local current density [8] } \\
\text { 3. Number of active anodic } \\
\text { areas and anodic site locations } \\
\text { (removable anodes) [8] } \\
\text { 4. Surface recovery time [8] } \\
\text { 5. Change wear mechanism } \\
\text { or force transition to } \\
\text { more/less severe loss rates }\end{array}$ \\
\hline Tribo-corrosion & $\begin{array}{l}\text { 1. Effects friction } \\
\text { 2. Local pH of environment } \\
\text { (where appropriate) } \\
\text { 3. Total mass loss from } \\
\text { surface (mechanical } \\
\text { and electrochemical) }\end{array}$ \\
\hline Wear debris & $\begin{array}{l}\text { 1. Generation of metallic } \\
\text { debris causes secondary } \\
\text { ion release as } \\
\text { debris react with environment } \\
\text { and corrode themselves. }\end{array}$ \\
\hline
\end{tabular}


electrochemical cell. The effects of applied potential and oscillation frequency were evaluated for micro-motions of 50 and $100 \mathrm{pm}$ amplitude. The extent of wear was strongly influenced by the applied potential, especially for potentials above approximately $-0.2 \mathrm{~V} \mathrm{Ag} / \mathrm{AgCl}$. This effect was related to the increasing oxidation of the third body formed by plastic deformation of the metal found at higher anodic potentials. On the other hand, the mechanical energy necessary for wear was found to be dramatically decreased when anodic potentials were applied.

1.5.2. Medical significance of tribo-corrosion. Researchers are becoming increasingly interested in metal-on-metal (MoM) joint implants with studies being focused on their wear and corrosion (ion release) behaviour and the subsequent influence on human biology. The corrosion, wear and wearcorrosion behaviour for three materials (high carbon CoCrMo, low carbon CoCrMo and UNS S31603) have been discussed by Yan et al [11]. Corrosion effects on the overall performance for the three materials are analysed. Two distinct regimes have been found for the three materials: (a) the running-in regime and (b) the steady state regime. Even in the steady state regime, $20-30 \%$ of the material degradation can be attributed to corrosion-related damage. High carbon CoCrMo showed excellent corrosion, wear and corrosion-wear resistance and therefore it delivered the best overall performance in terms of a lower wear rate, a lower friction coefficient and a higher resistance to corrosion. The role of proteins in the joint fluids and attachment onto surfaces are thought to play a key role but this mechanism is not well understood.

\subsection{Aims of this review}

The aim of this review is to overview research into the wear-corrosion of engineering coatings and dental overlays. It will identify the coating systems that have been, or are being, investigated and, wherever possible, identify their application and suitability for industrial environments. It will highlight the additional issues associated with coated surfaces compared with monolithic surfaces as well as the main degradation mechanisms. It also aims to discuss the current state of the art in the understanding of the interactions between mechanical wear processes and electrochemical and/or chemical processes. Appropriate models will also be reviewed. However, the subject area is in its infancy and the literature, to date, is dispersed making generic conclusions difficult and the conclusions that can be made are very coating/substrate/environment system specific.

\section{Wear-corrosion interactions}

Wear-corrosion interactions can be defined as follows. The total damage under erosion-corrosion, $T$, can be represented as:-

$$
T=E+C+S
$$

while under wear-corrosion, the total damage, $T$, is given by (i.e. sliding or abrasive wear):

$$
T=W+C+S
$$

where $E$ is the pure erosion material loss, $W$ is the mass loss due to wear, $C$ is the solids free flow corrosion rate and $S$ is the synergistic or interactions term. There are numerous interactions between wear and corrosion and almost as many ways experimentally to quantify them. Mostly these interactions are referred to as synergistic and quantify the level of synergy. Synergy is defined as 'the difference between wear-corrosion and the summation of its two parts' and can be expressed by equation (4).

$$
S=T-(E+C)=\left(\Delta C_{\mathrm{e}}+\Delta E_{\mathrm{c}}\right),
$$

where $T, C$ and $E$ are typically gravimetric terms relating to wear-corrosion, electrochemical corrosion without triboinfluence and mechanical wear mechanisms, respectively. The interactive processes can be broken down into two components, $\Delta E_{\mathrm{c}}$ and $\Delta C_{\mathrm{e}}$, where $\Delta E_{\mathrm{c}}$ is the corrosion-enhanced wear and $\Delta C_{\mathrm{e}}$ is the wear-enhanced corrosion. Recent literature has defined $\Delta E_{\mathrm{c}}$ as the synergy term and $\Delta C_{\mathrm{e}}$ as the additive term.

For the erosion case, the synergistic effect (interactive term), $S$, is referred to as $\Delta E_{\mathrm{c}}$ or $\left(\Delta C_{\mathrm{e}}+\Delta E_{\mathrm{c}}\right)$ depending on the literature source and under what conditions $C$ has been obtained. Thus care must be taken when extracting synergistic levels for different materials when using multiple sources of literature. The $S$ terms and how they should be measured are given by the ASTM G119-93 standard which is a useful guide to evaluate synergy [12].

Wear can mechanically strip the protective corrosion film creating fresh reactive corrosion sites and producing $\Delta C_{\mathrm{e}}$ [13], dependent on the rate of repassivation and the integrity of the film formed. Other possible wearenhanced corrosion mechanisms include (i) local acidification at wear sites, accelerating corrosion rates and prohibiting film formation, (ii) increased mass transport by high turbulence levels, (iii) lowering the fatigue strength of a metal by corrosion, (iv) anodic wear scars can cathodically polarize the surrounding unworn surfaces and destabilize passive films in these regions enhancing corrosion [14] and (v) surface roughening of the specimen during wear-enhanced mass transfer effects increasing the corrosion rate [15]. Corrosionenhanced wear mechanisms are also possible $\left(\Delta E_{\mathrm{c}}\right)$. The $\Delta E_{\mathrm{c}}$ wear rate could be due to (vi) the removal of work hardened surfaces by corrosion processes which expose the underlying base metal to erosion mechanisms [16], (vii) preferential corrosive attack at grain boundaries resulting in grain loosening and eventual removal [17], (viii) the increase in the number of stress concentration defects resulting from micropitting and (ix) detachment of plastically deformed flakes on the metal surface due to stress corrosion cracking. Most of the above mechanisms, if dominant, would be expected to lead to positive synergy.

Malka et al [18] give an example of where positive synergies are dominant and have looked at whether erosion enhances corrosion and/or corrosion enhances erosion in pipe loop experiments on uncoated AISI 1018 carbon steel in $1 \mathrm{wt} \%$ $\mathrm{NaCl}$ solutions purged with $\mathrm{CO}_{2}$ (partial pressure of 1.2 bar) and containing $2 \mathrm{wt} \%$ silica sand $(275 \mu \mathrm{m})$. They found that erosion enhances corrosion and corrosion enhances erosion but the dominant synergistic effect was that of corrosion on erosion i.e. $\Delta E_{\mathrm{c}}$. For roughly equal corrosion $(C)$ and erosion rates 


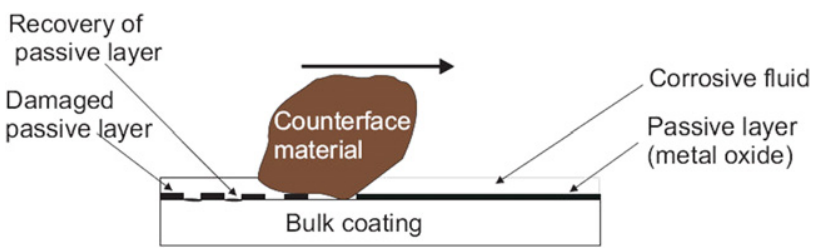

Figure 5. Type I wear-corrosion of hard coatings on metallic substrates where damage to the passive film results in repassivation and healing of the passive film on the coating.

$(E)$ the total mass loss $(T)$ was equal to 2 to 3 times $(E+C)$ showing significant synergy under $2 \mathrm{~m} \mathrm{~s}^{-1}$ flow velocities.

However, in some instances negative synergy can occur, called an antagonistic effect. Possible antagonistic mechanisms which reduce wear rates $\left(-\Delta E_{\mathrm{c}}\right)$ are $(\mathrm{x})$ reduced shot-peening [19] by high velocity sand particle impacts or (xi) the presence of a soft or loosely adherent corrosion film reducing contact stresses or (xii) blunting of the crack tips by lateral dissolution retarding the speed of crack propagation. The reduction in corrosion rates $\left(-\Delta C_{\mathrm{e}}\right)$ could result from (xiii) rapid corrosion film growth (xiv) scaling or the formation of a passive film reducing corrosion rates dramatically or (xv) thermally affected films.

The situation is further complicated for coatings, particularly porous coatings or those with substantial crack systems, where subsurface corrosion can occur at the interface with the substrate or interlayers. Corrosion products can be transported from these subsurface sites through interconnecting porosity or crack networks and be ejected out of the surface pores in the coating and into the tribological contact area. These products could be of different composition to the coating and have a dramatic effect on tribo-corrosion losses. It is also likely that the $\mathrm{pH}$ within pores and other such occluded sites within coatings could be very different from the bulk electrolyte and could accelerate corrosion of the coating and voluminous corrosion products will exert additional stresses to those imposed by tribological contact and enhance degradation mechanisms.

Dearnley and Aldrich-Smith [20] have proposed three major wear-corrosion mechanisms of coated metallic systems that are of types I, II and II. These are schematically represented in figures 5, 6 and 7, respectively. Type I relates to the removal or damage of passive films on coatings and their healing by repassivation. Mild wear-corrosion interactions are expected from this mechanism. Type II, however, relates to galvanic attack of the substrate leading to blistering and removal of the coating under sliding contacts. Larger wearcorrosion interactions are expected from this mechanism. Type III relates to galvanic attack of the counter face which is subsequently roughened, leading to abrasion of the coating during subsequent sliding.

The possible interactions for erosion-corrosion have been plotted as a function of potential and velocity to create regime maps to help identify conditions that have acceptable mass loss rates and avoid conditions that accelerate loss rates [21]. Examples of experimental attempts to quantify synergy for erosion-corrosion of coatings by aqueous slurries are given in Wood [22-25]. These have led to quantitative maps of electrochemical $(C)$ and mechanical $(T-C)$ contributions
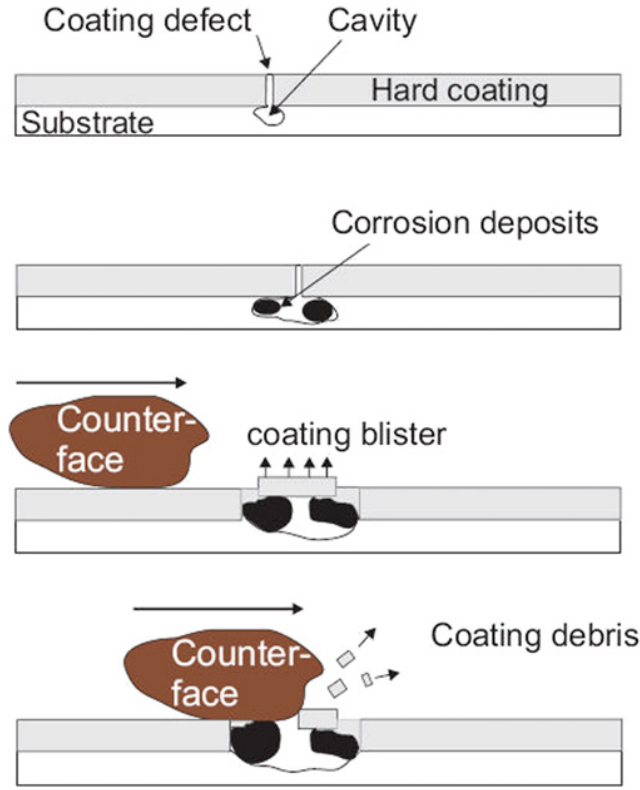

Figure 6. Type II: corrosion-wear of hard coated metallic alloy. Pitting/blistering of the hard coating culminates in mechanical fragmentation and removal of the coating.
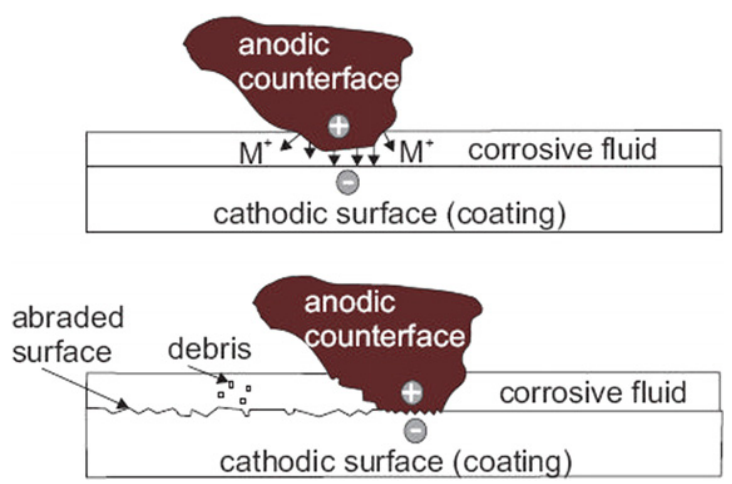

Figure 7. Type III wear-corrosion due to the galvanic roughening of the counter face which increases abrasion of the coating during subsequent sliding.

to material loss under wear-corrosion and allow regimes of surface performance to be identified. Regimes are identified by using the ratio of $(T-C) / C$ with erosion-corrosion having values between 1 and 10 , mechanically dominated wear being greater than 10 while corrosion-erosion has values between 0.1 and 1 and corrosion dominated has values less than 0.1. Figure 8 shows an example for a HVOF nickel aluminium bronze coating on carbon steel, uncoated carbon steel and cast nickel aluminium bronze. These maps are useful for considering compositions for improved resistance by highlighting whether mechanical or electrochemical aspects need to be inhibited. Figure 9 illustrates a similar map for abrasion-corrosion of various surfaces including sintered cermets, stainless and duplex stainless steels as well as thermally sprayed tungsten carbide coatings.

The trend at present in tribo-corrosion is away from quantifying synergy as it usually involves strong debates over how it was quantified. Sometimes gravimetric and electrochemically derived mass losses are needed and scant 
regard is given to the cumulative errors that arise when calculating any interactive term such as $\Delta C_{\mathrm{e}}$ or $\Delta E_{\mathrm{c}}$. The current author prefers the approach of isolating mechanical and electrochemical or chemical contributions as the balance between these can inform surface selection or suggest improved coating microstructure/compositions. The focus should be on the resultant total wear rate $(T)$ as this needs to be minimized to yield optimum component life.

In situ electrochemical techniques are required to investigate the charge transfer reactions and quantify dissolution rates in contacts subject to wear-corrosion. Electrochemical techniques are used to determine the corrosion current or surface potential transients occurring in real-time during tribo-corrosion experiments. Celis et al [26] caution against simple analysis of monitoring the surface open circuit potential (OCP) during tribo-corrosion tests as this analysis requires in-depth understanding of the mechanical, chemical

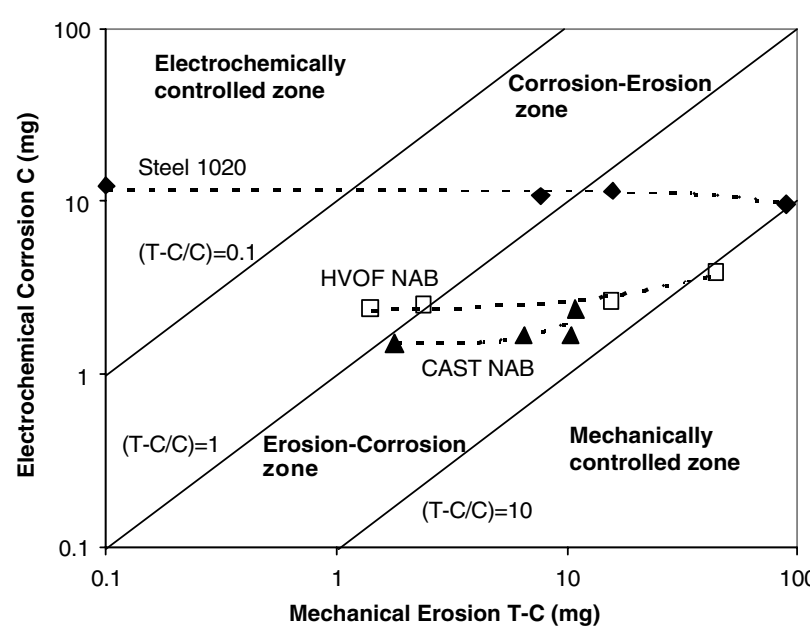

Figure 8. Erosion-corrosion regime map with electrochemical material loss versus mechanical material loss for erosion-corrosion of carbon steel AISI 1020, HVOF nickel-aluminium bronze coating and cast nickel-aluminium bronze under jet impingement conditions with $2 \%$ w/w sand in seawater. Reprinted with permission from [24]. Copyright 2007 Elsevier. and electrochemical effects on OCP. Time and load dependent microstructural and surface modifications of materials as well as mass transport conditions at the interface between material and electrolyte must be taken into consideration and these are often ill-understood. Figure 10 is an example of OCP and corrosion current measuements made with a micro-abrasion rig operating under 3-body rolling abrasion conditions abrading a $250 \mu \mathrm{m}$ thick thermally sprayed WC-10Co-4Cr coating on stainless steel 316 for a sliding distance of $90 \mathrm{~m}$ using $5 \mu \mathrm{m}$ $\mathrm{SiC}$ abrasives suspended in $\mathrm{NaOH}$ solutions of $\mathrm{pH} 11$ at room temperature. The potential is seen to fall in the electronegative direction once abrasion commences indicating the surface is more active and then starts to return to more positive values once abrasion stops. The resultant current is seen to increase on abrasion starting due to depassivation and remains constant at $2 \mu \mathrm{A}$ for the duration of the test before returning towards zero as the surface repassivates after abrasion stops.

\section{Models}

Recent progress in modelling and understanding of tribocorrosion systems has been discussed by Landolt [27]. Some models are mentioned below to illustrate the rationale behind them and although they are developed for homogeneous, passive and bulk surfaces they could be useful to model the consequences of tribo-corrosion of some coatings and also perhaps the penetration of thin coatings by wear creating a galvanic corrosion cell between unworn coating and the exposed substrate.

Published research has tried to deal with the synergistic effects between wear and corrosion processes which result in accelerated material loss and in some cases actually decelerate material loss [28-31]. A wide range of corrosion resistant materials rely on a relatively thin surface oxide film to provide a barrier (of high impedance) to charge transfer (and thus corrosion) between the relatively active bulk material and the corrosive environment. This film renders the surface passive but within tribo-corrosion contacts the passive film will be removed by mechanical wear or impingement processes. Where the film is mechanically removed, charge transfer

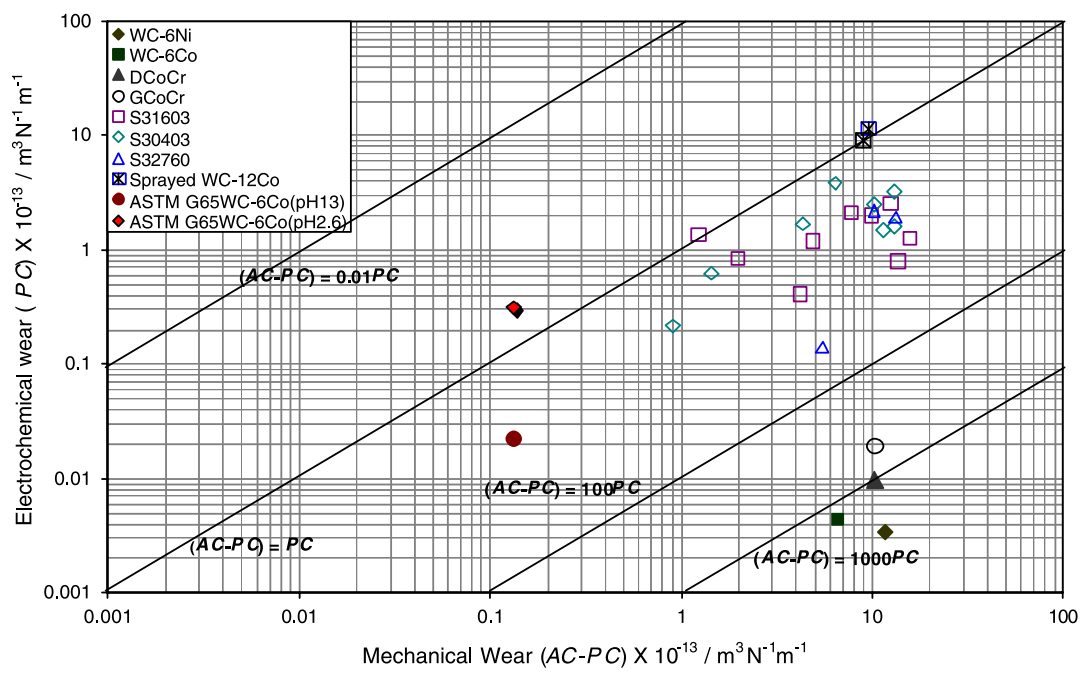

Figure 9. Tribo-corrosion mechanism regime map. Data points used are taken from $[42,43,65,66]$. 


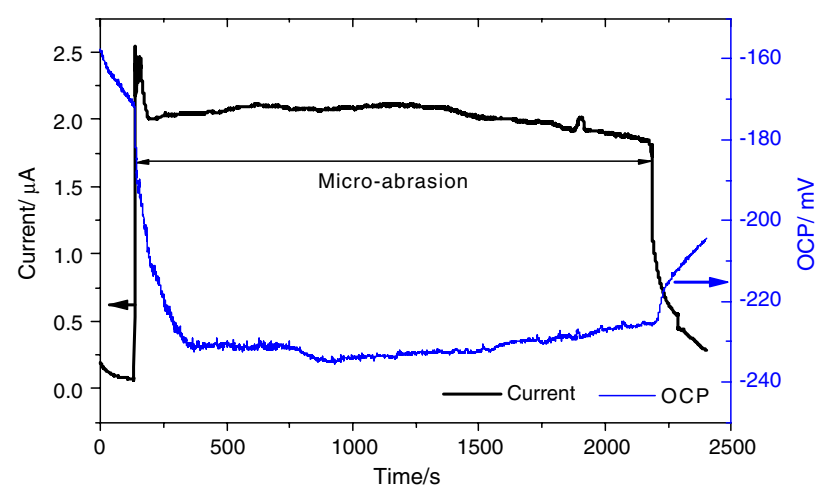

Figure 10. OCP and current as a function of time during micro-abrasion of $250 \mu \mathrm{m}$ thick $\mathrm{WC}-10 \mathrm{Co}-4 \mathrm{Cr}$ coating on stainless steel 316 for a sliding distance of $90 \mathrm{~m}$ using 0.16 volume fraction slurry of $4.5 \mu \mathrm{m} \mathrm{SiC}$ abrasives suspended in $\mathrm{NaOH}$ solution of $\mathrm{pH}$ 11. The applied load was $0.2 \mathrm{~N}$ and a zirconia ball of $25.5 \mathrm{~mm}$ dia was rotated to give a sliding velocity of $0.05 \mathrm{~ms}^{-1}$.

can occur at the interface without retardation from the barrier film [32]. This interaction between tribological and electrochemical corrosive effects causes materials to corrode at a different rate from that experienced under pure wear conditions. Some models based on this understanding are being developed to predict electrochemical activity within wear-corrosion contacts and these will be discussed below:

\subsection{Increased currents due to sliding contacts}

Typically passive oxide films are responsible for the corrosion resistance of metallic surfaces. However, these oxides are vulnerable when subjected to tribological contact conditions where mechanical effects can damage or completely remove these films. This typically leads to accelerated corrosion in regions of damaged or removed oxide films (Mischler et al [33]).

Ponthiaux et al [34] suggest that the galvanic activity resulting from worn areas surrounded by unworn areas is very important in tribo-corrosion contacts. Garcia et al [35] developed a model for the current $I$ that flows through an electrode of area $A$ at a given anodic potential when subjected to a reciprocating wearing contact with a frequency of $f$ as

$$
I=f A_{\mathrm{a}} \int_{0}^{1 / f} i_{\mathrm{a}}(t) \mathrm{d} t+f\left(A-A_{\mathrm{a}}\right) \int_{0}^{1 / f} i_{\mathrm{p}}(t) \mathrm{d} t,
$$

where $A_{\mathrm{a}}$ is the worn area, $A-A_{\mathrm{a}}$ is the passive area, $i_{\mathrm{a}}(t)$ is the repassivation current density, $i_{\mathrm{p}}(t)$ is the passive current density at a given anodic potential.

A more elaborate model has been developed by Goldberg and Gilbert [36] for currents generated by scratching passive surfaces. Their model has the form

$$
I(t)=I_{\text {peak }} \mathrm{e}^{\left[-\left(t-t_{0}\right) / \tau\right]}+I_{\infty} .
$$

If Tafel behaviour is applicable then

$$
I_{\text {peak }}=j_{\text {crit }} A_{0} \mathrm{e}^{\left[n_{\mathrm{f}} / b_{\mathrm{a}}\right]}+\frac{\delta \rho Z F A_{0}}{M_{\mathrm{w}} \tau},
$$

where $I_{\text {peak }}$ is the peak current $\left(I_{\text {peak }}=I_{\max }-I_{\infty}\right), I_{\max }$ is the maximum recorded current, $\tau$ is the time constant for repassivation, $t_{0}$ is the time to produce the scratch, $I_{\infty}$ is the passive current at $t=\infty, j_{\text {crit }}$ is the current density for passivation, $A_{0}$ is the scratch area, $n_{\mathrm{f}}$ is the scratch overpotential, $b_{\mathrm{a}}$ is the Tafel slope, $\delta$ is the repassivated oxide thickness, $\rho$ is the oxide density, $Z$ is the charge per cation, $F$ is Faraday's constant and $M_{\mathrm{w}}$ is the oxide molar mass.

Mischler et al [37] have developed a model for reciprocating contacts that includes the effects of load and material hardness. He modelled the anodic current $I_{\mathrm{a}, \mathrm{w}}$ generated by wear induced by a hard insulating counter body.

$$
I_{\mathrm{a}, \mathrm{w}}=K_{\mathrm{w}} l f\left(\frac{W}{H}\right)^{1 / 2} \int_{0}^{1 / f} \mathrm{i} \mathrm{d} \tau .
$$

More complex models are being developed for tribo-corrosion interactions in aqueous sliding contacts, see [38].

It is extremely important to recognize the roles of reactive species in affecting the tribological processes and to understand the processes of tribo-corrosion interactions. Jiang and Stack [39] discuss the mechanisms of wear debris generation and the roles of reactive species in the generation of wear debris during sliding wear in gaseous or aqueous environments. The effects of the environment on the development of wear-protective layers are highlighted as important to controlling mass loss levels.

\subsection{Increased currents due to erosion-corrosion}

Erosion damage by solid particle impact or cavitation bubble collapse to an oxide or passive film will reveal the underlying nascent surface inducing a higher activity (higher corrosion current), for a limited duration, than for the intact oxide surface. Bozzini et al [40] employed a simple approximate model using a 'recovering target' concept. This model has an advantage in that it can be applied to both passivating and actively corroding conditions. The impacting particles are modelled with rigid monodisperse spheres of radius $r_{\mathrm{p}}$. The particle impact process is assumed to be Poissonian with parameter $\lambda$ (impacts $\mathrm{m}^{-2} \mathrm{~s}^{-1}$ ). It is assumed that each impact gives rise to an alteration of the corrosion rate through a localized change in corrosion current density for a period of time, relating to a recovery to the affected state. The effective corrosion current density, $i_{\text {corr }}\left(\mathrm{nA} \mathrm{cm}^{-2}\right)$, at a given electrode potential (typically the corrosion potential) can be related to the mechanically affected corrosion component of the synergistic damage through a coefficient, $f_{\mathrm{a}}$, (such that $0 \leqslant f_{\mathrm{a}} \leqslant 1$ ) expressing the fraction of the corroding surface which is affected by the erosive action of impinging particles, by equation (9):

$$
i_{\text {corr }}=C+\Delta C_{\mathrm{e}}=f_{\mathrm{a}} i_{\mathrm{a}}+\left(1-f_{\mathrm{a}}\right) i_{\mathrm{u}}
$$

where the subscripts a and $\mathrm{u}$ stand for 'affected' and 'unaffected', respectively. The current densities $i_{\mathrm{a}}$ and $i_{\mathrm{u}}$ are characteristic of the corroding material in the absence and in the presence of the erosive action and can be measured separately by means of suitable experiments. In general, the coefficient $f_{\mathrm{a}}$ can be defined in equation (10):

$f_{\mathrm{a}}=\left(\frac{\text { no. of impacts }}{\text { control area }}\right) \times\left(\frac{\text { damaged area }}{\text { impact }}\right)$

$$
\times \text { recovery time }=\lambda A_{\mathrm{a}} \tau,
$$

where $A_{\mathrm{a}}=$ affected surface area and $\tau=$ passive recovery time. 
Table 2. Results from the electrochemical measurements and erosion-corrosion tests at $2.35 \mathrm{~m} \mathrm{~s}^{-1}, 100 \mathrm{~g} \mathrm{l}^{-1}$ silica sand (size between $100-500 \mu \mathrm{m}), 20^{\circ} \mathrm{C}[48]$.

\begin{tabular}{|c|c|c|c|c|c|}
\hline \multirow[b]{2}{*}{ Coating } & \multicolumn{3}{|c|}{$\begin{array}{l}\text { Electrochemical measurements } \\
\text { Corrosion rate }\left(\mathrm{mm} \mathrm{yr}^{-1}\right)\end{array}$} & \multicolumn{2}{|c|}{$\begin{array}{l}\text { Erosion-corrosion } \\
\text { rate }\left(\mathrm{mm} \mathrm{yr}^{-1}\right)\end{array}$} \\
\hline & $\mathrm{NaOH}$ & $\mathrm{H}_{2} \mathrm{SO}_{4}$ & Seawater & $\mathrm{NaOH}$ & Seawater \\
\hline $\mathrm{WC}-\mathrm{Cr}_{3} \mathrm{C}_{2}-\mathrm{Ni}$ & 0.38 & 0.15 & & 0.4 & \\
\hline $\mathrm{Cr}_{3} \mathrm{C}_{2}-\mathrm{NiCr}$ & 0.17 & 0.077 & & 0.17 & \\
\hline WC-Co & & & 0.76 & & 1.6 \\
\hline $\mathrm{WC}-\mathrm{Co}-\mathrm{Cr}$ & & & 0.32 & & 0.55 \\
\hline $\mathrm{Cr}_{2} \mathrm{O}_{3}-\mathrm{Al}_{2} \mathrm{O}_{3}-\mathrm{TiO}_{2}$ & $3.2 \times 10^{-5}$ & $3.6 \times 10^{-5}$ & & 0.27 & \\
\hline $\mathrm{Cr}_{2} \mathrm{O}_{3}$ & $7.6 \times 10^{-3}$ & $1.5 \times 10^{-3}$ & & 0.35 & \\
\hline
\end{tabular}

Equation (13) indicates an accelerating element to corrosion caused by film damage or removal and is one element of the complex interactions between erosion and corrosion that needs to be understood. Bozzini et al [40] also shows that annealed carbon steel has a more active corrosion potential before it was work hardened resulting in $i_{\mathrm{u}}>i_{\mathrm{a}}$ and by using equation (13) shows a reduction (i.e. a negative synergy or antagonism) in overall corrosion rate with erosion present.

\section{Tribo-corrosion of different coating types}

Modern surface engineering research is looking into depositing a wide range of hard phases such as carbides along with corrosion resistant metal binder elements with the aim of achieving good adhesion between carbides and binders and therefore successfully combining corrosion and wear resistant elements together. Recent research has shown that this solution has difficulties, as Souza and Neville [41] and Bello et al [42] and Thakare et al [43] show, the performance of WC-Co-Cr systems can suffer localized corrosion of the carbide phases, thereby compromising the performance of such surfaces as well as the importance of composition and integrity of $\mathrm{Cr}$ based passive films.

Thermal spray techniques such as high velocity oxy-fuel (HVOF) are increasingly being used for depositing wearcorrosion coatings [44]. Other coating processes, involving chemical vapour deposition (CVD) have been used to produce ultra-hard coatings such as diamond for pump components and mechanical seals [45-47].

\subsection{Thermally sprayed coatings}

Using ceramic-metallic (cermet) or hard oxide coatings to protect metallic components is an effective method to reduce wear and corrosion. Generally cermet coatings consist of WC or $\mathrm{Cr}_{3} \mathrm{C}_{2}$ particles embedded in a metal binder, which can be a pure metal or a mixture consisting of $\mathrm{Ni}, \mathrm{Cr}$ or $\mathrm{Co}$. Hard oxide coatings are typically based on $\mathrm{Cr}_{2} \mathrm{O}_{3}$.

Toma et al [48] examined the erosion and corrosion resistance of coatings produced by HVOF spraying at ambient temperatures in $0.1 \mathrm{M} \mathrm{NaOH}$ and $0.1 \mathrm{M} \mathrm{H}_{2} \mathrm{SO}_{4}$ solutions containing sand. Wear-corrosion tests showed that the corrosion properties of the sprayed coatings strongly affect the material loss rate under wear-corrosion conditions. This work emphasises the importance of the corrosion resistance and passivity of the binder as coatings with less corrosion resistant matrix enhanced erosion. Also the erosion mechanism of the carbide coatings seems to be controlled by the skeletal network of the carbides. For comparison, flame and plasma sprayed hard $\mathrm{Cr}_{2} \mathrm{O}_{3}$ coatings were examined. Due to the high impedance of the coating, the corrosion rate was very low. Table 2 shows corrosion and erosion-corrosion rates for the coatings tested by Toma which were exposed to solutions of $\mathrm{NaOH}$ or $\mathrm{H}_{2} \mathrm{SO}_{4}$ as well as seawater and show that the environment has a major influence on corrosion rates and that the addition of sand impingement increases material loss rates except for the $\mathrm{Cr}_{3} \mathrm{C}_{2}-\mathrm{NiCr}$ coating in $\mathrm{NaOH}$.

The role of binder corrosion in the erosion-corrosion degradation of HVOF thermally sprayed $\mathrm{WC}-\mathrm{Co}-\mathrm{Cr}$ coatings has been studied by Souza and Neville [41] using electrochemical polarization techniques in a $3.5 \% \mathrm{NaCl}$ solution at varying temperatures. They report that initially corrosion proceeds primarily by dissolution of the Co phase, depending on the integrity and thickness of the passive film (thought to be mainly $\mathrm{Cr}_{2} \mathrm{O}_{3}$ ) on the binder phase. Similar observations are reported for other compositions of thermally sprayed cermet coatings ( $\mathrm{WC}-\mathrm{CrNi}$ and $\mathrm{WC} / \mathrm{CrC}-\mathrm{CoCr}$ ) [49]. The dissolution of the binder matrix phase at the hard phase/matrix interface is a known mechanism for synergy contributing to $\Delta E_{\mathrm{c}}$. The action of erosion is also likely to weaken the hard phase/matrix interface and after cyclic loading from repeated solid particle impacts could lead to crack initiation at the interface. Binder dissolution issues are also seen to control the erosion-corrosion rates for 50(WC + $12 \mathrm{Co}$ ) balance $\mathrm{NiCrSiFeC}$ and $\mathrm{WC}-17 \mathrm{Co}$ coatings studied by Bjordal et al [50].

Permeation of electrolyte into these cracks could induce localized environments which are dramatically different (i.e. low $\mathrm{pH}$ ) from the bulk conditions and induce crevice corrosion, which in turn contributes to increased $\Delta C_{\mathrm{e}}$ levels. The influence of the spraying parameters (spraying distance, barrel length and kerosene flow rate) on the tribo-corrosion performance of HVOF sprayed WC-17Co coatings has been studied by Valentinelli et al [51]. They also found that binder dissolution controlled wear-corrosion levels and therefore coating compositions should be designed with reference to the relevant Pourbaix diagrams (potential versus $\mathrm{pH}$ regime maps based on thermodynamic considerations only) to select compositions that are passive in the service environment and in addition have strong repassivation tendencies.

$\mathrm{Cr}_{3} \mathrm{C}_{2}$ coatings typically have lower wear resistance but greater fracture toughness than $\mathrm{WC}-$ Co based coatings as seen by Fedrizzi et al [52]. They used a sliding contact (blockon-ring) with a silicon carbide counter face in $3.5 \% \mathrm{NaCl}$ 


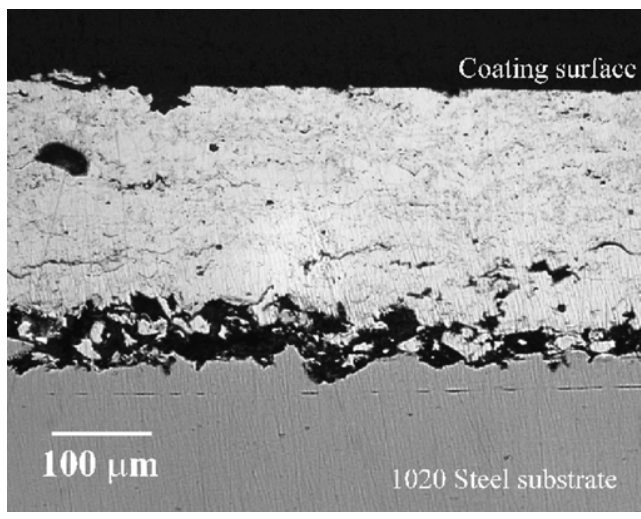

Figure 11. Disbonded HVOF aluminium bronze coating under erosion-corrosion conditions due to electrolyte ingress to the coating/substrate interface followed by corrosion of the carbon steel substrate and the generation of voluminous corrosion product accelerating crack propagation at the coating/substrate interface.

solutions at $0.3 \mathrm{~m} \mathrm{~s}^{-1}$ sliding speeds. The increased fracture toughness was seen to limit crack initiation during surface grinding compared with WC-Co systems. They also found the composition of binders important, with the $\mathrm{NiCr}$ alloy exhibiting faster repassivation characteristics compared with the Co-based binders.

HVOF coatings with compositions of $86 \mathrm{WC}-10 \mathrm{Co}-4 \mathrm{Cr}$ or corrosion resistant alloys such as nickel aluminium bronze have been considered for wear-corrosion applications, Souza and Neville [41], Wood and Speyer [53] and Barik et al [54]. Of particular concern is the level of porosity ( $>2 \%$ ) within the coatings which can accelerate crack propagation and coating removal under erosion and can also be interconnected such that electrolyte can permeate into the coating/substrate interface accelerating through thickness corrosion of the coating and corrosion-driven coating-substrate disbondment, see figure 11. The erosion-corrosion performance of these coatings has been studied using free or submerged solidliquid slurry jets along with a mixture of gravimetric and electrochemical techniques. An example of monitoring the electrochemical potential of a coated steel specimen during erosion-corrosion jet impingement is shown in figure 12 . The potential signal detects electrolyte ingress and corrosion activity at the coating/substrate interface, see figure 13, as well as coating penetration by erosion. An additional concern with multiphase coatings (carbide/metal matrix) is the potential for debonding between the hard phase and the softer matrix which can accelerate surface degradation.

Coatings deposited with powders containing narrow grain size distributions are preferred as this provokes more controllable and homogeneous particle melting and avoids the particle size influence at a given flame temperature causing over or under heating of powder particles, Berget et al [55,56].

The influence of the corrosion characteristics of the substrate is also important and can play a vital role in the coated system performance. Al-Fadhli et al [57] studied the erosioncorrosion characteristics of HVOF thermally sprayed Inconel 625 coatings on different metallic surfaces that simulated coating over weld repaired or refurbished surfaces found in the offshore industry, namely, bulk stainless steel and a spotwelded stainless steel and a composite surface of welded

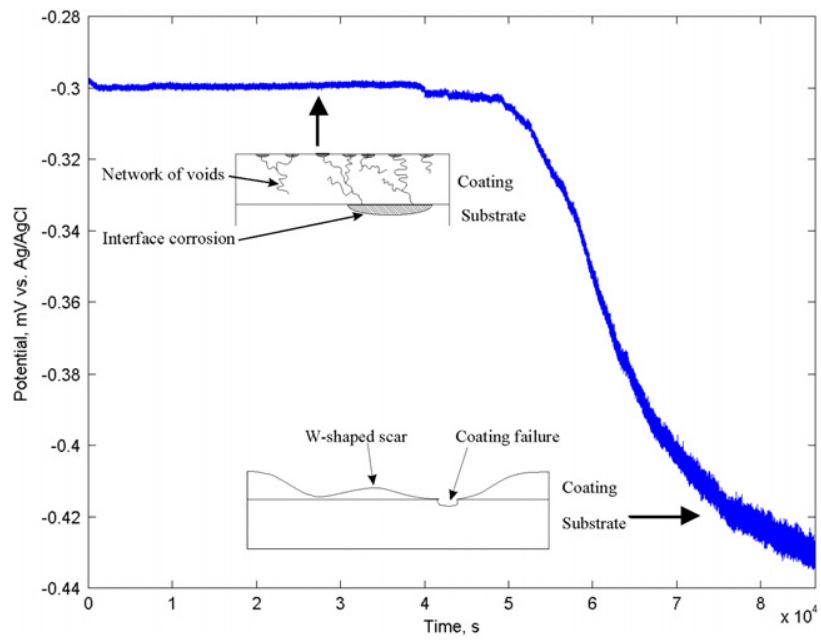

Figure 12. Potential-time curve of a HVOF aluminium bronze coating on AISI 1020 steel substrate under slurry erosion conditions in $3.5 \% \mathrm{NaCl}$. Reprinted with permission from [62]. Copyright 2002, Elsevier.

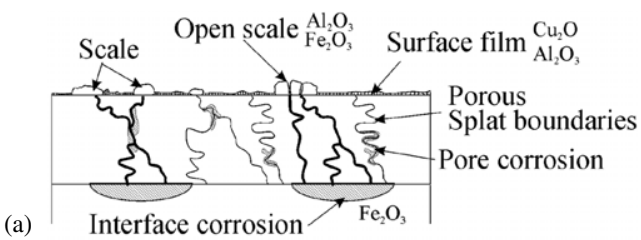

(b)

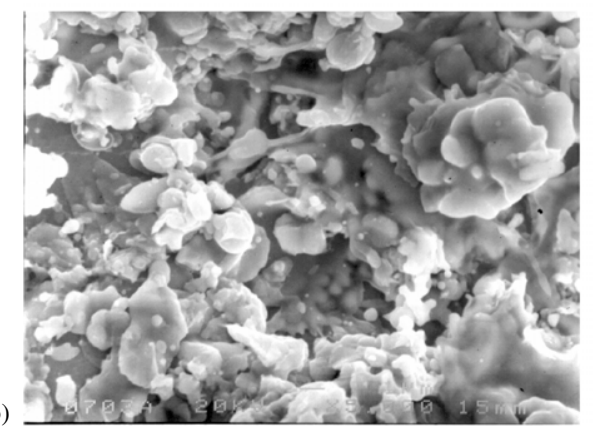

Figure 13. (a) Schematic of crack systems in coating generated during erosion-corrosion and the subsequent substrate corrosion and ejection of corrosion products from through-coating corrosion onto the coating surface.

stainless steel and carbon steel. Their results indicate that the coating over both spot-welded and plain stainless steel surfaces exhibited a similar degree of weight loss. However, the coating on the composite surface experienced a greater degree of weight loss and spallation due to electrolyte ingress through the porous coating and subsequent corrosion of the carbon steel substrate. Microscopic observations of the fracture surfaces showed that the metal removal from the surface was concentrated around the unmelted and the semi-melted particles of the weld deposit.

Post-coating treatments are a potential way to remove some of the detrimental microstructural features and offer a way to improve the tribo-corrosion performance of coatings. Liu et al [58] show the potential benefits of laser treated HVOF Inconel 625- and WC-based coatings. Improved corrosion and wear resistance was related to the removal of the 
discrete splat-structures, porosity and micro-crevices as well as the reduction of micro-galvanic activity by compositional gradients between the WC and the matrix due to the formation of interfacial phases. In addition the improved wear resistance was also associated with the formation of rapid solidification microstructure with faceted dentritic WC phases. A significant reduction in wear was observed when the laser treatment completely dissolved the WC. Inconel 625-42WC coatings appeared the best for wear but Inconel 625-22WC was better against static corrosion in $3.5 \% \mathrm{NaCl}$ solution.

As many coatings have complex compositions the possibility of micro-galvanic corrosion activity between the different microstructure and the composition is likely to undermine surface integrity. This has been seen in the corrosion and corrosion-wear behaviour of HVOF sprayed WC cermet coatings with metallic binders of $\mathrm{Co}$, $\mathrm{Co}-\mathrm{Cr}$, $\mathrm{CrC}-\mathrm{Ni}$ and $\mathrm{Ni}$, in a strong acidic environment by Cho et al [59]. Considerable micro-galvanic corrosion occurred between the WC particles and the binder, and uniform corrosion occurred in the binder materials of WC-Co, WC-Ni. In spite of the presence of $\mathrm{Cr}$, the overall corrosion resistance of the $\mathrm{WC}-\mathrm{CrC}-\mathrm{Ni}$ coating was inferior to that of the $\mathrm{WC}-\mathrm{Co}-\mathrm{Cr}$ coating due to electrolyte permeation to the coating/substrate interface through interconnecting micro-cracks. The friction coefficient of the coatings without $\mathrm{Cr}$ was lower than that of the coatings containing $\mathrm{Cr}$ under the corrosion-wear conditions, probably due to lubricious corrosion products within the contact.

The tribo-corrosion performance of nanostructured coatings has also been recently studied for biomedical applications. Basak et al [60] have studied the corrosion and wear-corrosion behaviour of a thermal sprayed nanostructured $\mathrm{FeCu} / \mathrm{WC}-\mathrm{Co}$ coating in a simulated human body fluid (Hank's solution) and compared this with stainless steel AISI 304 and nanostructured WC-Co coatings. The multiphase structure of the $\mathrm{FeCu} / \mathrm{WC}-\mathrm{Co}$ coating induced complex corrosion processes but exhibited a depassivation/repassivation behaviour comparable to that of stainless steel AISI 304 and the nanostructured WC-Co coatings.

The ability of the coating surface to repassify quickly after the passive film is mechanically damaged is clearly key to being able to minimize the dissolution losses during wearcorrosion. To understand the repassivation kinetics in such complex mechanical and electrochemical environments is not straightforward but some electrochemical techniques may be applicable. For example, electrochemical noise measurements have been used to investigate the interactions between erosion and corrosion of HVOF aluminium, aluminium bronze and aluminium-silicon coatings, Tan [61] and Wood [62]. Although perturbations (noise) on the corrosion current measurements represented multiple sand particle impacts, valuable insights into the mass transport and repassivation kinetics occurring under erosion-corrosion were obtained. Examples of electrochemical current noise are given in figures 14 and 15 for flow corrosion and erosion-corrosion respectively. Ratios of standard deviation of noise have been used to infer repassivation properties of coatings under erosion-corrosion conditions, see figure 16.

Identifying the wear-corrosion mechanisms and regimes the coating will experience in service is also an important

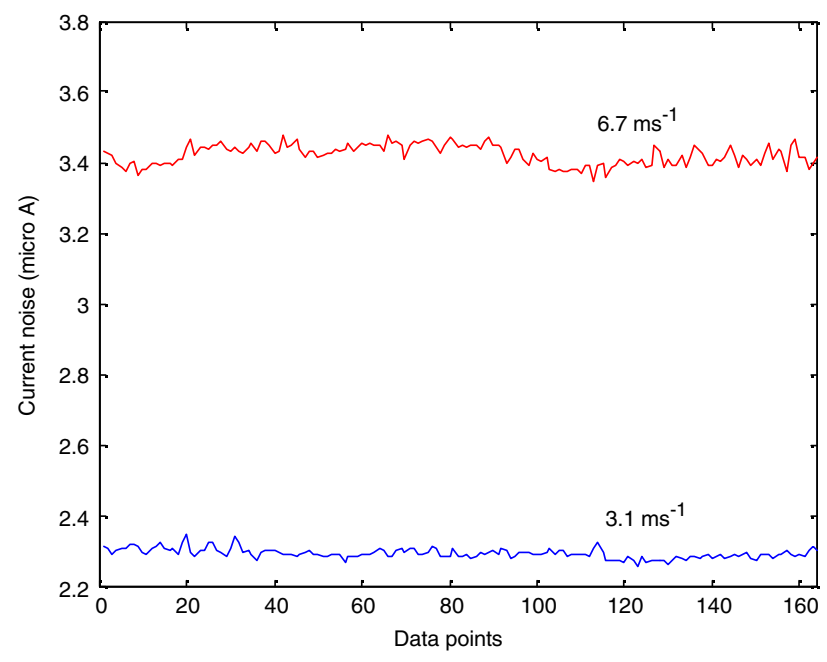

Figure 14. Flow corrosion currents for HVOF NAB coating held at OCP under $90^{\circ}$ jet impingement conditions with jet velocities of 3.1 and $6.7 \mathrm{~ms}^{-1}$.

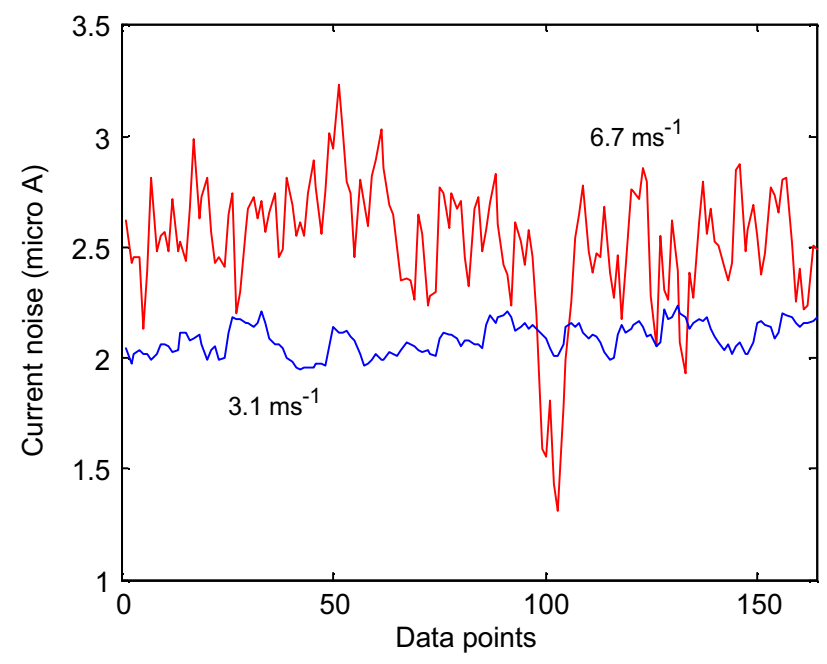

Figure 15. Erosion-corrosion currents for HVOF NAB coating held at OCP under $90^{\circ}$ slurry jet impingement conditions with jet velocities of 3.1 and $6.7 \mathrm{~m} \mathrm{~s}^{-1}$ and $2 \% \mathrm{w} / \mathrm{w}$ sand in seawater slurry.

consideration when designing or selecting coatings. Regimes vary from being mechanically dominated to being completely corrosion dominated and require quite different properties from the coatings. Stack and Abd El Badia [63], evaluated the erosion-corrosion of thermally sprayed composite-based coatings (WC/Co-Cr) 8-10 $\mu \mathrm{m}$ thick (relatively thin for these types of coating systems) in synthetic sea water with a $\mathrm{pH}$ 8.2. Silica sand of size $50-250 \mu \mathrm{m}$ at 4,6 and $8 \mathrm{wt} \%$ concentrations were used in a slurry jet velocity of $3 \mathrm{~m} \mathrm{~s}^{-1}$ at $90^{\circ}$ to the sample surface. Erosion-corrosion maps were constructed by plotting the concentration of solids versus the surface potential. The dominant erosion-corrosion mechanism and the level of wastage are also noted on the maps as well as the type of interaction between the tribological and corrosion processes. These maps show that changes in the slurry concentration and surface potential affect the material removal mechanism. This approach has been extended to multilayer $\mathrm{CrN} / \mathrm{NbN}$ 'superlattice' coatings by Purandare et al [64]. 


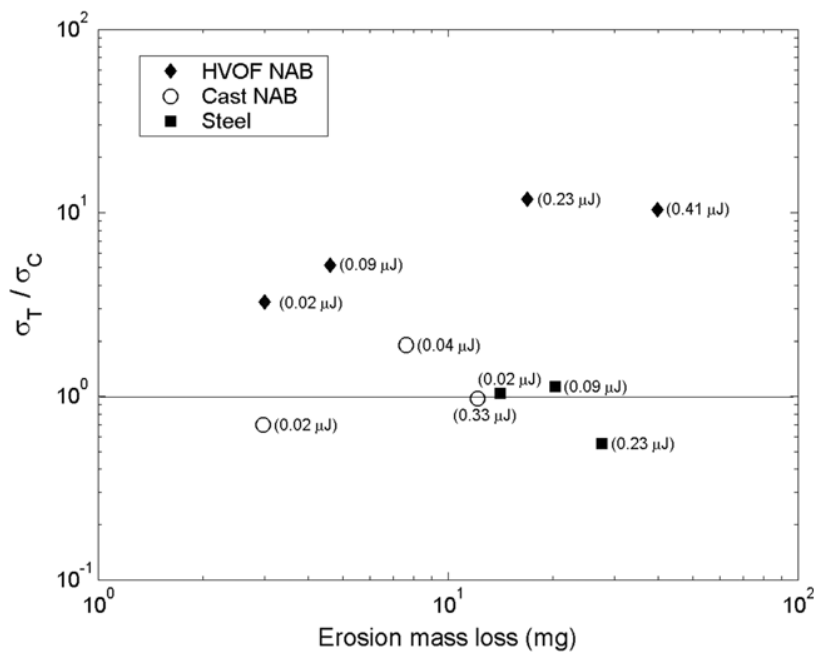

Figure 16. Standard deviation ratios of electrochemical current noise from erosion-corrosion divided by flow corrosion levels plotted against erosion mass loss by gravimetric analysis for carbon steel AISI 1020, HVOF NAB coating and cast NAB under jet impingement conditions with and without $2 \% \mathrm{w} / \mathrm{w}$ sand in seawater. Reprinted with permission from [54]. Copyright 2005, Elsevier.

To date, relatively little work has looked at abrasioncorrosion of coatings. Gant et al [65] and Shipway and Howell [66] have examined microscale wear testing of WCCo sintered hardmetals and coatings. Generally, it has been observed that microscale abrasion of both the sintered and coating materials occurs predominantly by preferential removal of the binder phase followed by pullout of the carbide. Binder phase removal was found to be accelerated by corrosion in acid media.

The microscale abrasion-corrosion performance of two WC-10Co-4Cr thermally sprayed coatings have been compared with two sintered hardmetals, WC-6Co and WC-11Ni. Tests were performed using both $\mathrm{NaOH}$ ( $\mathrm{pH} 11$ ) and neutral $\mathrm{SiC}$ aqueous slurries, and contrary to expectations, micro-abrasion under alkaline conditions resulted in lower wear rates producing a mildly negative synergy $(S / T=-8 \%$ to $-18 \%$ ), with the exception of the sintered $\mathrm{WC}-11 \mathrm{Ni}$, see [43]. The synergistic effects of the detonation gun (D-gun) sprayed WC-10Co-4Cr coating was further studied under alkaline conditions by Thakare et al [67]. Comparisons between surfaces pre-exposed to electrolyte and freshly polished coating surfaces in strong $\mathrm{NaOH}$ solutions ( $\mathrm{pH} 11$ ) show that significantly lower wear rates were seen for the exposed surface due to a negative wear-corrosion synergy. The negative synergy was seen to increase with increasing sliding distances for both fresh and exposed surfaces. The physical mechanisms of this negative synergy were thought to relate to preferential corrosion of metallic tungsten at the carbide/binder interface resulting in a more compliant surface under abrasion conditions that reduce material loss, see figures 17 and 18 .

As stated earlier, crack propagation in the coatings that result in interconnecting paths between the substrate and the electrolyte can degrade the coating performance. Giroud et al [68] have shown the benefits of epoxy impregnation of different oxide based coatings $\left(\mathrm{Cr}_{2} \mathrm{O}_{3}, \mathrm{Al}_{2} \mathrm{O}_{3}, \mathrm{Al}_{2} \mathrm{O}_{3}+\mathrm{Cr}_{2} \mathrm{O}_{3}\right)$ studied under sliding wear tests in sea water.

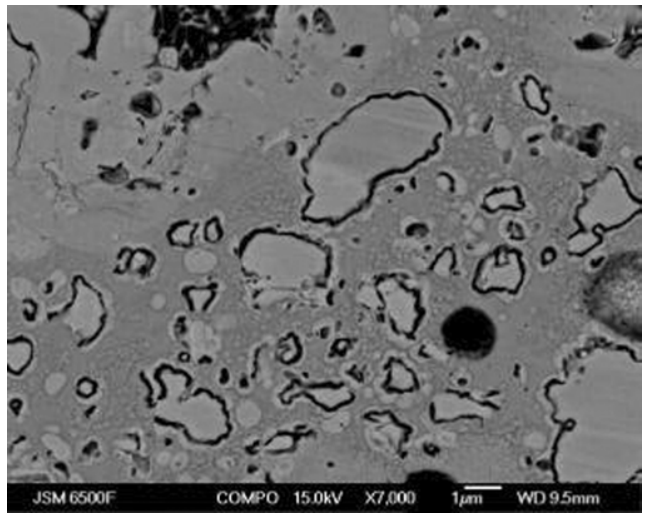

Figure 17. Selective corrosion of $\mathrm{W}$ and $\mathrm{W}_{2} \mathrm{C}$ phases (which are formed due to decarburization of WC) around the periphery of the carbide grain when exposed to an alkaline environment of $\mathrm{pH} 11$ for $168 \mathrm{~h}$. Reprinted with permission from [67]. Copyright 2007, Elsevier.

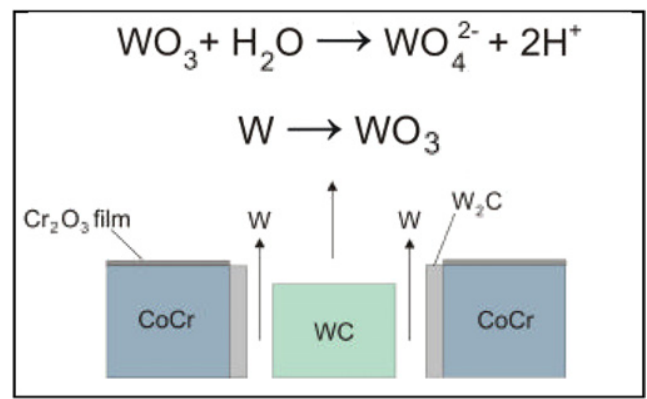

Figure 18. Schematic showing the selective corrosion of $\mathrm{W}$ and $\mathrm{W}_{2} \mathrm{C}$ phases in a WC- $10 \mathrm{Co}-4 \mathrm{Cr}$ coating.

\subsection{Plasma sprayed coatings}

Bulloch and Callagy [69] made an 'in situ' examination of the thinning characteristics of four different protective coatings in an effort to extend the service life of induced draft fan blades which had a history of failing after less than two years of service. Normally, during service, a Mg-based additive was used to neutralize the $\mathrm{pH}$ of the flue gases. However, when no such additions were made, the conditions quickly became extremely acidic with the ash deposits containing over $70 \%$ sulfate and having a $\mathrm{pH}$ of 1.9. During these acidic conditions the thinning rates were accelerated. A plasma sprayed Nicrome $80 / 20$ coating was found to exhibit the best resistance to such acidic conditions.

The effect of aluminum phosphate sealing treatments on the wear and corrosion behaviour of air plasma sprayed bulk oxide ceramics of alumina and chromia coatings have been studied by Knuuttila et al [70]. Wet abrasion tests in kaolin-water and silica-water mixtures were used while slurry erosion tests were performed in a slurry pot tester. Aluminium phosphate sealing is shown to be an effective method to improve the slurry erosion and wet abrasion resistance of chromia coatings even at low $\mathrm{pH}$ values. The addition of kaolin to water increased the wet abrasion rates of the alumina coatings through a tribo-chemical reaction. The sealing treatment did not offer any improvement in resistance to wearcorrosion for the alumina coatings. 
Little research appears to have been conducted on the cavitation-corrosion of coatings and the limited work there has focused on plasma ion plating or plasma assisted diffusion. For example, the combination of high fracture toughness and corrosion resistance of $\mathrm{Ni}-\mathrm{Al}$ intermetallic materials has been shown to produce good cavitation resistance. The cavitation performance of a cathodic arc plasma ion-plated $\mathrm{Ni}-\mathrm{Al}$ film on AISI 1045 carbon steel has been studied by Chang et al [71]. Three coating compositions were studied, $\mathrm{Ni}-48 \mathrm{Al}, \mathrm{Ni}-40 \mathrm{Al}$ and $\mathrm{Ni}-30 \mathrm{Al}$, and all increased the cavitation erosion resistance of the substrate by 10 times and the erosion-corrosion resistance to $3.5 \% \mathrm{NaCl}$ solutions by 2 times and to $3.5 \% \mathrm{HCl}$ solutions by 3 times. The potentiodynamic polarization data of coated specimens in these two electrolytes indicated that the coated specimens exhibited a more electropositive corrosion potential and lower corrosion current density than the bare substrate material. However, cavitation erosion induced pitting corrosion of the substrate and this accelerated the mass loss rate of the specimens.

Chernega et al [72] found cyclic cavitation-erosioncorrosion interactions increased the material loss of complex carbide coatings by between 1.5 and 2 times the continuous cavitation rates. They found cyclic cavitation-corrosionwear processes on HVOF carbide coatings based on $\mathrm{Cr}$, $\mathrm{Cr}-\mathrm{Zr}, \mathrm{Cr}-\mathrm{Nb}, \mathrm{Cr}-\mathrm{Si}$, $\mathrm{Nb}$ were enhanced by $10-20 \%$ in $\mathrm{NaCl}$ solutions compared with pure water. The cyclic cavitationcorrosion treatment enhanced the corrosion processes by 2-4 times compared with a continuous cavitation-corrosion influence. This enhancement was related to the destruction of the protective surface oxide films, the removal of corrosion products and the increase in micro-cracks in the diffusion coating as a result of microshocks produced by near surface cavitation bubble collapse.

\subsection{Plasma electrolytic oxidation (PEO) coatings}

Under erosion-corrosion conditions it has been shown that an erodent with kinetic energy $<0.016 \mu \mathrm{J}$ only removes the surface asperities of PEO alumina based coatings on an aluminium alloy substrate. At higher energies of $0.061 \mu \mathrm{J}$, removal of the outer layer was evident, assisted by crack enhancement resulting in gross delamination at the PEO coating/Al substrate interface. The PEO alumina coating did offer higher erosion-corrosion resistance at relatively low impingement energies compared with either cast or HVOF sprayed nickel aluminium bronze surfaces. This superior performance of the PEO coating is probably due to its being 3-6 times harder, Barik et al [73].

Nie et al [74] report improved abrasive wear and corrosion resistance for PEO coatings on Al 6082 compared with the untreated aluminium alloy. They used dry and wet rubber wheel abrasion tests and found that wet abrasion removed more material than the uncoated samples due to the reduced surface temperatures and re-oxidation levels when water was present. No difference in the dry and wet wear rates was seen for the PEO coatings.

\subsection{Plasma vapour depsition (PVD) coatings}

Decorative thin films used on personal items and mobile phones are exposed to aggressive chemical environments such as human sweat and at the same time suffer wear from the touch of a hand or cleaning procedures. Tribocorrosion of decorative single layer zirconium oxynitride $\mathrm{ZrO}_{x} \mathrm{~N}_{y}$ films (approximately 3-6 $\mu \mathrm{m}$ thick) have been studied recently [75]. Such films have potential use on watches, writing instruments and spectacle frames. The presence of oxygen allows the film properties to be tailored between those of metallic nitrides, $\mathrm{MN}_{y}$, and those of the corresponding insulating oxides $\mathrm{MO}_{x}$. Altering the metallic/covalent and ionic bonding characteristics allows the mechanical, electrical, chemical and optical properties of such materials, including their colour, to be tuned. The performance of such films is dependent on the deposition method and on both the concentration and distribution of the nitrogen atoms within the matrix. Reciprocating tribo-corrosion tests using an alumina pin in an artificial sweat solution of $\mathrm{pH} 4.5$ show that the dissolution of the M2 tool steel substrate governs the degradation which typically occurs by delamination induced by preferential dissolution of the substrate. This highlights the dangers of the use of thin coatings which are, or become, porous during tribo-contacts and subsequently allow substrate corrosion. Friction measurements show high initial values of 0.4 to 0.5 , attributed to corrosion products and debris in the contact, but steady-state values of around 0.15 are reached after the film fractures and the alumina pin contacts the steel substrate.

The meat casing industry works with highly fibrous materials and with low $\mathrm{pH}$ conditions. Natural casings are extracted from the digestive tract of edible animals, for example, the submusosa, a collagen layer of the intestine. Artificial casings made from collagen and cellulose are often used for sausages and cold meats in preference to the expensive natural casings. The artificial casings are tougher and easier to manufacture. The casings are extruded from a slurry of collagen and cellulose which is acidic $(\mathrm{pH} 1$ to $\mathrm{pH} 3)$. This gel is pumped and extruded through a mixer that must be highly abrasion-corrosion resistant. Failure of this equipment is often attributed to this corrosive medium and abrasion or, most commonly, a combination of both. Coatings are thus required to protect the pump surface and maintain the operational conditions. TiN-PVD coatings approximately $5 \mu \mathrm{m}$ thick on AISI M2 steel have been studied by Damborenea et al [76] as an alternative to the stainless steels currently being used to extend the pump lifetime. The TiN coating with a singlelayer configuration was tested in contact with edible slurry of $6 \%$ solids (collagen plus $30 \%$ cellulose) with an average fibre length of $300 \mu \mathrm{m}$ and a $\mathrm{pH} 2$ to simulate conditions in the meat casing industry. Experiments were also run on full scale pumps as well as with a corundum $3 \mathrm{~mm}$ diameter ball-on-disc tribometer at $0.04 \mathrm{~m} \mathrm{~s}^{-1}$ and $1 \mathrm{~N}$ load in air $(<40 \% \mathrm{RH})$ and acidic solution. The TiN coating was found to fragment when sliding in dry air and the presence of oxide debris of $\mathrm{N}_{x}-\mathrm{Ti}-\mathrm{O}_{y}$ composition suggested incomplete oxidation of the TiN.

In acidic solutions the friction reduced with increasing sliding distance to $\mu=0.01$. Pitting occurred either inside or just outside the wear track at pore sites in the coating allowing the electrolyte to permeate to the substrate/coating interface resulting in severe substrate dissolution and accelerating coating detachment into the casing solution. This coated system, therefore, suffered from significant synergism between 
abrasion and localized corrosion of the substrate via electrolyte permeation through interconnecting coating defects/pores. This failure mechanism is similar to those reported above by Ferreira et al [75] and to the substrate property dependence highlighted by Quan et al [77] and failures caused by poor coating quality seen by Dearnley and Aldrich-Smith [20].

A simple screening test has been developed by Dahm and Dearnley [78] to assess the suitability of surface coatings to protect the femoral articular surfaces of Ortron 90 (an austentitic stainless steel) total hip replacement prostheses from abrasion damage. Commercial PVD titanium nitride (TiN) and diamond-like carbon (DLC) coated Ortron 90 samples were subjected to this multi-scratch test. Adhesive and cohesive coating failures were observed at scratch intersections for all the coatings except the magnetron sputter deposited DLC coating which showed only through-coating fracture. Corrosion testing of the coated samples showed that the multiscratch grid introduced additional sites at which substrate corrosion could take place.

\subsection{Multilayered coatings}

PVD multilayer coatings offer coatings with multifunctional characteristics, lower residual stresses, good adherence to metallic substrates, improved hardness to toughness ratio and low friction coefficients. Holleck and Schier present results on multilayer coatings based on TiC/TiN [79]. Improved toughness due to fine grained microstructure, crack deflection, reduced stress concentrations, lower stress and strain fields and reduced residual stresses are reported.

Rossi et al [80] studied the wear-corrosion of $1 \mu \mathrm{m}$ thick TiN coatings (with and without the presence of a Ti interlayer) and ( $\mathrm{Ti}, \mathrm{Cr}) \mathrm{N}$ coatings under various wear conditions in a $0.1 \mathrm{M} \mathrm{NaCl}$ solution. The different behaviour was interpreted in terms of film cohesion, coating adhesion and residual stresses due to the PVD process. The (Ti,Cr)N deposits, which had the best intrinsic corrosion resistance, was the least resistant to wear-corrosion, probably because residual stress was much higher than in TiN, making the coating more brittle and poorly adherent to the substrate. The TiN/Ti samples showed the best behaviour under wear-corrosion, which was due to the enhanced adhesion offered by the titanium interlayer.

\subsection{Surface modification by plasma nitriding}

Plasma nitriding based surface modification techniques can be used to improve tribo-corrosion. Galliano et al [81] looks at the tribo-corrosion performance of a plasma nitrided Ti6Al4V alloy coating in natural $0.9 \mathrm{wt} \% \mathrm{NaCl}$ solutions under reciprocating alumina ball-on-flat sliding wear. Nitriding at $1173 \mathrm{~K}$ for $6 \mathrm{~h}$ gave better wear resistance without crack formation compared with samples nitrided at $973 \mathrm{~K}$ which micro-cracked causing coating failure and this improvement was attributed to a surface hardened layer of $\mathrm{TiN}-\mathrm{Ti}_{2} \mathrm{~N}$ approximately $15 \mu \mathrm{m}$ deep. Damage to the coating by sliding wear led to a galvanic current between the anodic wear track and the undamaged coating area. However, higher friction values were reported compared with untreated surfaces and the enhanced tribo-corrosion performance reduced once the hardened layer had worn through. Fernandes et al
[82] report the influence of low pressure plasma nitriding treatments of Ti6Al4V followed by plasma assisted oxidation at $700^{\circ} \mathrm{C}$. The oxidized surface layers were poorly crystallised with rutile and traces of anatase $\mathrm{TiO}_{2}$ nanocrystallites but nitriding hardened the surfaces and was found to improve tribocorrosion resistance.

Wang and Jaw [83] studied the effects of nitriding (at $1050^{\circ} \mathrm{C}$ and $20 \mathrm{~h}$ ) an austenitic alloy (Fe30Mn3Cr.7C with 2, 5, 6 and 9Al) under dry sliding reciprocating roller on flat geometries in air with a relative humidity of $55 \%$. They found the presence of an oxide layer critical in determining the dominant wear mechanism and wear rates. The unnitrided lower $\mathrm{Al}$ content alloys induced a mild tribo-oxidation wear process compared with the high $\mathrm{Al}$ containing alloys where severe abrasion, surface fatigue and delamination mechanisms were dominant. Nitriding was found to increase wear resistance by an order of magnitude for alloys equal to or above $5 \% \mathrm{Al}$ by inducing tribo-oxidation wear processes and increased hardness. The nitride layers were thought beneficial to support oxide layers generated by tribo-oxidation for alloys with less than $7.5 \% \mathrm{Al}$.

\subsection{Hard facings}

Erosion-corrosion can be a significant problem in the oil sands industry. Neville et al [84] have studied four tungsten carbide (WC) metal matrix composites with different particle size distributions applied by plasma-transferred arc (PTA) weld overlay. The overlays comprised $65 \mathrm{wt} \% \mathrm{WC}$ hard phase with a metal matrix binder consisting of mainly $\mathrm{Ni}$, $\mathrm{Cr}, \mathrm{Si}, \mathrm{B}$ and $\mathrm{Fe}$. In static corrosion tests, little change in the corrosion rate was seen for the different WC grain sizes but under erosion-corrosion the larger grain size WC-based MMC showed a reduction in resistance. This emphasizes the complex relationship between grain size and erosion and corrosion resistance.

Reyes and Neville [85] focus on materials used for the body of offshore drill bits and examine the performance of cobalt-based alloy (Stellite X40), a WC/Cu-based solid matrix as a solid body bit replacement material and a WC/Ni-based cermet spray-fused coating used as a hardfacing material. The binding materials suffered general corrosion as erosion shifted the materials from a pseudo-passive regime to an actively corroding regime leaving the hard particles exposed, which enhanced the mechanical erosion. Synergy levels were found to be $50 \%$ (i.e. $S / T=0.5$ ) but the main finding was that the cobalt alloy showed superior erosion-corrosion resistance compared with the two metal-matrix composites.

\subsection{Electrodeposited coatings}

In a review of alternatives to thermal spray coatings, Tucker [86] highlights the need to avoid interconnecting pores and the ingress of electrolyte to the substrate and galvanic couples between coatings and substrates. Electroplating, he proposed, is one route to deposit fully dense coatings but these are prone to crack and need interlayers to resist interfacial corrosion. Autocatalytic coatings such as nickel-phosphorous offer defect-free solutions if deposited correctly but composite electroplating allows the co-deposition of fine particles of metallic or non-metallic compounds into the plated layers 
in order to improve the surface properties. Lekka et al [87] compared the performance of pure nickel and $\mathrm{Ni}-\mathrm{SiC}$ nanostructured coatings and the results indicate that the codeposition of nickel and $\mathrm{SiC}$ nanoparticles leads to uniform deposits possessing 1.6 times higher abrasion resistance and double the corrosion resistance to salt spray attack as well as more stable friction under wear-corrosion conditions. Benea et al [88] studied the wear-corrosion performance of these coatings in a $0.5 \mathrm{M} \mathrm{Na}_{2} \mathrm{SO}_{4}$ neutral solution. The nanocomposite coating showed a higher polarization resistance and reduced corrosion current density compared with the pure nickel coating under sliding wear conditions. The coefficient of friction of the nanocomposite coating was lower than that of the pure nickel coating. Wang et al [89] have developed nanocrystalline functionally graded $\mathrm{Ni}-\mathrm{Co} / \mathrm{CoO}$ surfaces for tribo-corrosion applications. Graded $\mathrm{Ni}-\mathrm{Co}$ structures from face-centred cubic at the nucleation face to hexagonal close packed at the growth face have been deposited along with graded compositions from a Ni-rich interface to a Co-rich coating surface. Surface layers of dense but ultrafine CoO approximately 3-4 $\mu \mathrm{m}$ thick with a $\left(\begin{array}{llll}1 & 1 & 1\end{array}\right)$ preferred orientation have generated improved corrosion resistance to $\mathrm{NaCl}$ and $\mathrm{NaOH}$ solutions.

Hard chromium coatings are used for coating components on earthmovers, mining transport systems or moulds for plastics. Fedrizzi et al [90] studied the mechanisms of tribocorrosion of hard chromium coated steel bars in sodium chloride solutions under sliding wear. They observed that the degradation mechanism was primarily adhesive wear with some secondary abrasive wear and localized corrosion. The synergy was $15 \%$ of the total mass loss under tribo-corrosion conditions with an order of magnitude increase in corrosion current due to mechanical processes.

\section{Tribo-oxidation}

The high temperatures induced in tribo-contacts or exposure of surfaces to high process temperatures can lead to tribooxidation and the formation of tribo-chemical films that can protect or accelerate the degradation of surfaces. Instabilities of the tribo-chemical films and hence, the resulting wear rates, mean good tribological performance cannot be guaranteed. For example, Andersson and Blomberg [91] studied sintered silicon carbide sliding unlubricated on itself. Tribooxidation and surface fracture were identified as the dominant deterioration mechanisms with the oxidation products being silicon dioxide and, within narrow operational regimes, silicon monoxide. Part of the silicon dioxide wear debris was compacted under frictional heating to form smooth tribofilms on the mating surfaces, providing protection against excessive wear; the corresponding specific wear rates ranged from $10^{-6}$ to $10^{-5} \mathrm{~mm}^{3} \mathrm{~N}^{-1} \mathrm{~m}^{-1}$. The silicon monoxide, when formed, appeared as a loosely attached powder which provided no protection against wear, as indicated by a one order of magnitude increase in the wear rate.

The effects of the environment on the tribo-chemical effects are also important. The effects of atmospheric humidity on the formation of tribo-layers on PVD TiN coatings in contact with various steels and A356 Al-15\% SiC have been investigated by Wilson [92]. The TiN coatings suffered rapid wear by tribo-chemical oxidation and polishing at low sliding speeds and contact loads. This effect was reversed when the contact loads and sliding speeds were raised. Increasing the humidity increased the TiN wear rates and tribo-chemical wear was seen at low loads and speeds as well as extending into the higher loads and sliding speeds regions.

Again, as for other categories of coatings, the nature of tribo-induced mechanically mixed (shear zone) surface layers on the contacting surfaces is critical to the performance. This is seen by Fateh et al [93] who studied TiN and VN coatings deposited by reactive unbalanced magnetron sputtering in dry sliding tests conducted at temperatures between 25 and $700{ }^{\circ} \mathrm{C}$. Oxidation of TiN was detected between $600-700^{\circ} \mathrm{C}$ but had little effect on friction levels while the coefficient of friction for $\mathrm{VN}$ reduced continuously above $400{ }^{\circ} \mathrm{C}$ reaching 0.25 at $700^{\circ} \mathrm{C}$ due to the production and melting of $\mathrm{V}_{2} \mathrm{O}_{5}$. This is a self-lubricating property and is highly advantageous for the design of adaptive tribological surfaces. Surface layer formation is also important for the successful performance of titanium carbide and carbonitride coatings in dry sliding have been studied by Kostornov et al [94]. They found isomorphous oxide phases help form strongly adherent continuous and dense protective surface films.

Tribo-oxidation can be induced in sliding-rolling friction contacts such as those found in screw rotors used in compressors. Niebuhr et al [95] studied PVD-CrN and -TiN coatings, 6 to $10 \mu \mathrm{m}$ in thickness, in a high-speed twin roller geometry to mimic such conditions and found in air that the TiN spalled where the $\mathrm{CrN}$ coating suffered milder tribo-oxidation and had the lowest wear rate of the two coatings. Similar low wear rates were seen for the $\mathrm{CrN}$ coating under water lubricated conditions.

The friction of $\mathrm{Mo}_{2} \mathrm{~N}$ films sliding against an alumina ball in the temperature range of $20-400{ }^{\circ} \mathrm{C}$ is also sensitive to the formation of a surface oxide film, see Suszko et al [96]. At room temperature, friction leads to residual tribo-oxidation and an oxide film formation within the wear track resulting in low friction values of 0.4 and very low wear rates. At higher temperatures, the brittle oxide layer was worn away and the friction and wear increased. However, above $250^{\circ} \mathrm{C}$, oxide softening led to a pronounced decrease in friction.

The formation and composition of surface oxides induced by tribo-contacts can be strongly influenced when a lubricant is present. An example of this is given by Ouyang and Sasaki [97] who studied (V,Ti)N coatings deposited by cathodic arc ion plating (CAIP) reciprocating against a SAE 52100 steel ball between room temperature and $300^{\circ} \mathrm{C}$. Unlubricated, the $(\mathrm{V}, \mathrm{Ti}) \mathrm{N}$ coatings exhibited a friction coefficient of $0.57-$ 1.28 but these levels dropped to $0.18-0.19$ under boundarylubricated conditions. Metastable $\mathrm{FeO}$-type and stable $\mathrm{Fe}_{2} \mathrm{O}_{3}$ type iron-based oxides were seen to form on the worn surfaces under both boundary-lubricated and unlubricated conditions as well as some $(\mathrm{V}, \mathrm{Ti}, \mathrm{Fe})_{2} \mathrm{O}_{5}$ and rutile $\mathrm{TiO}_{2}$ oxides. The dissolved oxygen in the lubricant was identified as playing a major role in oxidational wear of these coatings under boundary-lubricated conditions.

Wear debris has a great influence on the friction and fretting wear of TiN coatings. It is generally understood that for such coatings under dry and ambient sliding conditions, the tribochemically formed $\mathrm{TiO}_{2}$ leads to high friction and wear. 
Table 3. Dental wear and wear-corrosion processes.

\begin{tabular}{|c|c|c|c|}
\hline Wear mechanism & Effect & Driving mechanism & Cause \\
\hline Abrasion & $\begin{array}{l}\text { Occlusal material } \\
\text { wear }\end{array}$ & $\begin{array}{l}\text { Frictional surface } \\
\text { interactions } 3-\mathrm{B} \text { abrasion }\end{array}$ & $\begin{array}{l}\text { Toothbrush/paste } \\
\text { Food bolus }\end{array}$ \\
\hline Attrition & $\begin{array}{l}\text { Changes surface } \\
\text { texture }\end{array}$ & $\begin{array}{l}\text { Sharp asperities } \\
\text { 2-B abrasion }\end{array}$ & $\begin{array}{l}\text { Antagonistic surface } \\
50 \% \text { harder than } \\
\text { the wearing surface }\end{array}$ \\
\hline Chemical wear & $\begin{array}{l}\text { Degrades silane } \\
\text { couplings in composites }\end{array}$ & Wetting & Food or saliva \\
\hline Surface fatigue & $\begin{array}{l}\text { Surface layer delamination } \\
\text { and severe roughening }\end{array}$ & $\begin{array}{l}\text { Rolling contacts and } \\
\text { cyclic loads }\end{array}$ & $\begin{array}{l}\text { Subsurface } \\
\text { stress concentrations }\end{array}$ \\
\hline Adhesive & $\begin{array}{l}\text { Platelet-shaped } \\
\text { wear transferred } \\
\text { to antagonistic surface } \\
\text { which can either reduce } \\
\text { or enhance wear rates. }\end{array}$ & $\begin{array}{l}\text { Asperity-asperity } \\
\text { interaction }\end{array}$ & $\begin{array}{l}\text { Shear } \\
\text { stresses }\end{array}$ \\
\hline
\end{tabular}

However, sliding in air with high relative humidity promotes the formation of hydrated $\mathrm{TiO}_{2-x}$ debris that act as a lubricant and can lower friction and wear.

The environmental conditions can also play a significant role in fretting wear levels as seen from work by Wu et al [98] who conducted sliding tests of PVD TiN coatings against corundum in $50 \%$ relative humidity air, in demineralized water, and in a $\mathrm{H}_{3} \mathrm{PO}_{4}$ solution. Both unidirectional and bidirectional sliding tests (fretting) were performed. Under bidirectional sliding, the coefficient of friction was lower, and the wear rate was higher than in unidirectional tests for both air and water; however, in phosphoric acid, a significant reduction in friction was noticed. The wear mechanisms identified were a mild tribo-oxidation mechanism in air and water, and a lubricating triboactivated phosphation mechanism in $\mathrm{H}_{3} \mathrm{PO}_{4}$. From these results, $\mathrm{H}_{3} \mathrm{PO}_{4}$ appears as a potential candidate for oil-free lubrication of uni- and bidirectional contacts.

Tribo-oxidation also occurs in fluidized bed boilers in the form of erosion-oxidation and therefore a $\mathrm{HVOF} \mathrm{Cr}_{3} \mathrm{C}_{2}-$ $\mathrm{NiCr}$ cermet coating has been studied by Wang and Luer [99] as candidates for such applications. They deployed a range of test conditions covering $25-750^{\circ} \mathrm{C}, 20-80 \mathrm{~m} \mathrm{~s}^{-1}, 15-90^{\circ}$ impact angles and different erodent feed rates and compared the performance against AISI 1018 carbon steel and other thermal spray coatings. The $\mathrm{Cr}_{3} \mathrm{C}_{2}-\mathrm{NiCr}$ cermet coating was found to have higher resistance at $30^{\circ}$ and $90^{\circ}$ impact angles and was attributed to its low porosity, fine grain structure and homogeneous distribution of hard carbides/oxides that form a skeletal network within a ductile and corrosion resistant matrix.

\section{Thick deposits/overlays—dental materials}

The use of artificial materials to replace natural dental tissue is common in dentistry. Due to health aspects there is concern about the risks that the corrosion and wear of these materials may induce on human biology. Linear wear and the release of wear particles are especially of interest. The insight into corrosion-wear processes in that field is, however, still in its infancy. Lambrechts et al [100] give an overview of the degradation processes that occur on artificial materials used in dentistry and more especially in restorative dentistry. Lightcured composite resins of inorganic silica fillers in organic (polymer) resins are currently seen as viable alternatives to

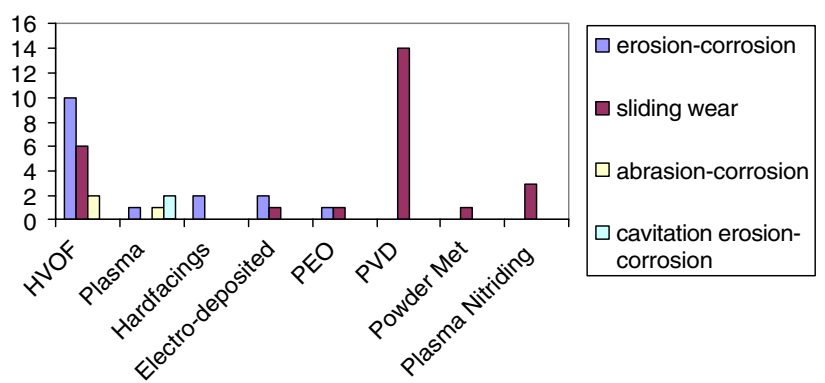

Figure 19. Number of papers published on tribo-corrosion of coatings by experiment used to assess performance and coating deposition process.

amalgam. Wear of dental composite resins involves adhesion, abrasion, attrition, chemical degradation and fatigue, see table 3. These mechanisms often act simultaneously and/or sequentially and interact with each other in a complex form making prediction of loss rates difficult.

Wear in the filled composites occurs by a complex set of processes involving tribo-chemical reactions between the filler particles and water, formation of surface films containing a mixture of filler fragments and reaction products and film delamination, as well as dissolution of the reaction products (Nagarajan et al [101]).

The contact wear behaviour of a dental ceramic composite containing $92 \mathrm{wt} \%$ silica glass and alumina filler particles in a polymeric resin matrix have been examined by Nagarajan et al [102]. Wear tests confirmed the presence of $\mathrm{Al}$ and other elemental constituents of the filler particles. It is proposed that three simultaneous processes occur at the sliding contact: tribo-chemical reactions and film formation, dissolution of the reacted products and mechanical removal of the film by microfracture. At low loads, wear occurs primarily by a tribochemical mechanism, i.e. formation and dissolution of the reaction products.

Lewis and Dwyer-Joyce [103] have reviewed the current understanding of wear of enamel and dentine in teeth and highlight the major influencing factors. They looked at various tribological conditions to which teeth are exposed. These include non-contact between opposing teeth, contact but no sliding and contact with sliding between opposing teeth. They emphasize that the largest single influencing factor is that of the 
Table 4. List of references for different coating deposition types and types of tribo-corrosion studies. HT = high temperature, $\mathrm{TO}=$ tribo-oxidation, bio = biotribo-corrosion.

\begin{tabular}{|c|c|c|c|c|}
\hline & Erosion-corrosion & $\begin{array}{l}\text { Sliding } \\
\text { wear-corrosion }\end{array}$ & Abrasion-corrosion & $\begin{array}{l}\text { Cavitation } \\
\text { erosion-corrosion }\end{array}$ \\
\hline HVOF & $\begin{array}{l}{[97](\mathrm{HT})} \\
{[41]} \\
{[53]} \\
{[54]} \\
{[49]} \\
{[55]} \\
{[56]} \\
{[61]} \\
{[62]} \\
{[63]}\end{array}$ & $\begin{array}{l}{[52]} \\
{[51]} \\
{[59]} \\
{[69]} \\
{[59]} \\
{[61]}\end{array}$ & $\begin{array}{l}{[66]} \\
{[67]} \\
{[65]}\end{array}$ & \\
\hline Plasma & [69] & & {$[70]$} & $\begin{array}{l}{[71]} \\
{[72]}\end{array}$ \\
\hline Hardfacings & $\begin{array}{l}{[84]} \\
{[85]}\end{array}$ & & & \\
\hline Electrodeposited & & $\begin{array}{l}{[90]} \\
{[88]}\end{array}$ & [87] & \\
\hline PEO & [73] & [73] & & \\
\hline 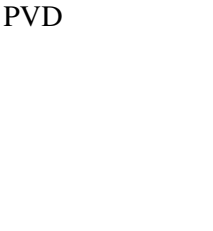 & [64] & $\begin{array}{l}{[74]+[92] \text { (TO) }} \\
{[75]+[93] \text { (TO) }} \\
{[81]+[95] \text { (TO) }} \\
{[77]+[96] \text { (TO) }} \\
{[89]+[97](\mathrm{TO})} \\
{[79]+[98] \text { (TO) }} \\
{[80]+[78] \text { (bio) }}\end{array}$ & & \\
\hline Plamsa Nitriding & & $\begin{array}{l}{[81]} \\
{[82]} \\
{[83]}\end{array}$ & & \\
\hline Powder met & & [94](TO) & & \\
\hline
\end{tabular}

chemical environment and this synergizes all wear mechanisms to enhance material loss rates. Research has shown that increasing acidity reduces both hardness and elastic modulus of enamel in an appropriate linear relationship without load or sliding between teeth. Material loss for both enamel and dentine increases with decreasing $\mathrm{pH}$ generated by acids found in soft drinks. Citric acid adjusted by $\mathrm{NaOH}$ and citric acid with titratable acidity give the highest loss rates. In the contact without sliding between teeth the enamel loss increases with increasing load or cyclic load. For contacts with sliding, a nonlinear relationship is seen with wear rates decreasing as the $\mathrm{pH}$ drops from 7 to 3 but increases when the $\mathrm{pH}$ is further decreased to $\mathrm{pH}$ 1. Up to now these synergistic and antagonistic effects between the effects of chemical and mechanical tooth wear have not been properly investigated.

\section{Conclusions}

Figure 19 summarizes the spread of coatings that have been the subject of published work in tribo-corrosion and reviewed in this paper. Overall there are relatively few papers reporting research into the tribo-corrosion of coatings but, of those reviewed, thermally sprayed HVOF coatings are the most common being the subject of erosion-corrosion and sliding wear-corrosion investigations while PVD coatings have also received some attention for sliding wear-corrosion applications. Table 4 shows the reference source per deposition technique and per tribo-corrosion test type. This table reveals a very sporadic approach to the research investigations into tribo-corrosion of coatings with many (often bespoke) wear-corrosion tests being run on specific (unique) coating compositions. It is, therefore, extremely difficult to gain generic insight into the fundamental behaviour from the published work. Most experiments test existing coatings that have been developed for either wear resistance or corrosion resistance. Coupling this to the fact that most corrosion resistant elements are not wear resistant and vice versa, these coatings, therefore, perform very badly when tested under combined wear-corrosion conditions. There is still considerable scope to design coatings specifically for wearcorrosion resistance with coating composition, microstructure, defect level, adhesion, cohesion and substrate properties being seen as some of the critical elements in coating performance in tribo-corrosion contacts. The influence of the corrosive environment is also shown to be important in controlling wear and friction as well as the evolution of near surface triboinduced layers which are critical in both erosion-corrosion and wear-corrosion situations. The one common issue, seen across all coating deposition types and compositions reviewed, is the need for high quality and fully dense coatings to remove substrate corrosion influences to improve coating life and to stop premature spallation. The review has identified the key interactions between wear and corrosion mechanisms that occur on a wide range of coating systems along with some models and mapping techniques that aim to inform coating selection and predict performance. However, these need major development before robust predictions can be made as our understanding of the mechano-electrochemical interactions that are present in tribo-corrosion is incomplete. 
The review also shows the need for more robust testing techniques with guidelines for reporting and analysis of results and in particular the need for post-test analysis of the coating surfaces. This may, for instance, include any tribo-layers or oxide films formed during contact and a record of the presence of third bodies or signs of substrate corrosion within the contact. Improved understanding of the electrochemical techniques being deployed is required, particularly where in situ data is being logged. There is also a strong need to develop mechano-electrochemical models to aid coating design and predict galvanic activity within the wear-corrosion scars.

\section{Acknowledgments}

The author is extremely grateful to Dr Julian Wharton and Mandar Thakare of the School of Engineering Sciences, University of Southampton, for helping to prepare the figures for this review and for their encouragement.

\section{References}

[1] Fischer A and Mischler S 2006 Tribocorrosion: fundamentals, materials and applications-editorial J. Phys. D: Appl. Phys. 39 issue 15, doi:10.1088/0022-3727/39/15/E01

[2] Celis J-P and Ponthiaux P 2006 Tribocorrosion—editorial Wear 261 937-8

[3] Hochstrasser-Kurz S, Mueller Y, Latkoczy C, Virtanen S and Schmutz P 2007 Analytical characterization of the corrosion mechanisms of WC-Co by electrochemical methods and inductively coupled plasma mass spectroscopy Corros. Sci. 49 2002-20

[4] Percy R J 1990 The operational performance of BP choke valves BP Engineering, Risers and Subsea Equipment Group 1990 BPE.90.ER152 (unpublished)

[5] Wood R J K, Mellor B G and Binfield M L 1997 Sand erosion performance of detonation gun applied tungsten carbide/cobalt-chromium coatings Wear 211 70-83

[6] Wheeler D W and Wood R J K 2005 Erosion of hard surface coatings for use in offshore gate valves Wear 258 526-36

[7] Allen C and Ball A 1996 A review of the performance of engineering materials under prevalent tribological and wear situations in South African industries Tribol. Int. 29 105-16

[8] Kok Y N, Akid R and Hovsepian P Eh 2005 Tribo-corrosion testing of stainless steel (SS) and PVD coated SS using a modified scanning electrode technique Wear 259 1472-81

[9] Barril S, Mischler S and Landolt D 2004 Influence of fretting regimes on the tribocorrosion behaviour of Ti6Al4V in 0.9 wt. \% sodium chloride solution Wear $256963-72$

[10] Barril S, Mischler S and Landolt D 2005 Electrochemical effects on the fretting corrosion behaviour of Ti6Al4V in $0.9 \%$ sodium chloride solution Wear 259 282-91

[11] Yan Y, Neville A and Dowson D 2006 Biotribocorrosion-an appraisal of the time dependence of wear and corrosion interactions: I. The role of corrosion J. Phys. D: Appl. Phys. 39 3200-5

[12] ASTM 1993 Standard Guide for Determining Synergism between Wear and Corrosion Standard G 119-93 (Conshohocken, PA: ASTM International)

[13] Zeisel H and Durst F 1990 Computations of erosion-corrosion processes in separated two-phase flows NACE Corrosion (NACE 1990) paper no 29

[14] Vignal V, Mary N, Ponthiaux P and Wenger F 2006 Influence of friction on the local mechanical and electrochemical behaviour of duplex stainless steel Wear 261 947-53
[15] Zhou S, Stack M M and Newman R C 1996 Characterization of synergistic effects between erosion and corrosion in an aqueous environment using electrochemical techniques Corrosion 52 934-46

[16] Matsumura M 1994 Erosion-corrosion of metallic materials in slurries Corros. Rev. 12 321-40

[17] Neville A, Hodgkiess T and Xu H 1999 An electrochemical and microstructural assessment of erosion- corrosion of cast iron Wear 235 523-34

[18] Malka R, Nešić S and Gulino D A 2007 Erosion-corrosion and synergistic effects in disturbed liquid-particle flow Wear 262 791-9

[19] Glaeser W and Wright I G 1986 Mechanically assisted degradation Metals Handbook vol 13, Corrosion 9th edn (Metals Park, OH: ASM International) pp 136-44

[20] Dearnley P A and Aldrich-Smith G 2004 Corrosion-wear mechanisms of hard coated austenitic 316L stainless steels Wear 256 491-9

[21] Stack M M and Abd El Badia T M 2006 Mapping erosion-corrosion of $\mathrm{WC} / \mathrm{Co}-\mathrm{Cr}$ based composite coatings: particle velocity and applied potential effects Surf. Coat. Technol. 201 1335-47

[22] Wood R J K 1992 Erosion-Corrosion synergism for multi-phase flowline materials La Houille Blanche No 7/8 pp 605-10

[23] Wood R J K 2006 Erosion-corrosion interactions and their effect on marine and offshore materials Wear 261 1012-23

[24] Wood R J K 2007 Erosion-corrosion Comprehensive Structural Integrity (Oxford, UK: Elsevier)

[25] Wood R J K 2004 Challenges of living with erosion-corrosion 2nd Int. Symp. on Advanced Materials for Fluid Machinery (London: IMechE) pp 113-32

[26] Celis J-P, Ponthiaux P and Wenger F 2006 Tribo-corrosion of materials: interplay between chemical, electrochemical, and mechanical reactivity of surfaces Wear $261939-46$

[27] Landolt D 2006 Electrochemical and materials aspects of tribocorrosion systems J. Phys. D: Appl. Phys. 39 3121-7

[28] Wood R J K, Puget Y, Trethewey K R and Stokes K 1998 The performance of marine coatings and pipe materials under fluid-borne sand erosion Wear 219 46-59

[29] Wood R J K and Hutton S P 1990 The synergistic effect of erosion and corrosion: trends in published results Wear 140 387-94

[30] Stack M M, Zhou S and Newman R C 1995 Identification of Transitions in erosion-corrosion regimes in aqueous environments Wear 186-187 523-32

[31] Naerheim Y and Kendig M W 1985 The influence of electrochemical potential on wear Wear 104 139-50

[32] Stemp M, Mischler S and Landolt D 2003 The effect of mechanical and electrochemical parameters on the tribo-corrosion rate of stainless steel in sulphuric acid Wear 255 466-75

[33] Mischler S, Spiegel A and Landolt D 1999 The role of passive oxide films on the degradation of steel in tribocorrosion systems Wear 229 1078-87

[34] Ponthiaux P, Wenger F, Drees D and Celis J-P 2004 Electrochemical techniques for studying tribocorrosion processes Wear 256 459-68

[35] Garcia I, Drees D and Celis J-P 2001 Corrosion-wear of passivation materials in sliding contacts based on a concept of active wear track area Wear 249 452-60

[36] Goldberg J R and Gilbert J L 1997 Electrochemical response of CoCrMo to high-speed fracture of its metal oxide using an electrochemical scratch test method J. Biomed. Mater. Res. 37 421-31

[37] Mischler S, Debaud S and Landolt D 1998 Wear-accelerated corrosion of passive metals in tribocorrosion systems J. Electrochem. Soc. 145 750-8

[38] Jiang J, Stack M M and Neville A 2002 Modelling the tribo-corrosion interaction in aqueous sliding conditions Tribol. Int. 35 669-79 
[39] Jiang J and Stack M M 2006 Modelling sliding wear: from dry to wet environments Wear 261 954-65

[40] Bozzini B, Ricotti M E, Boniardi M and Mele C 2003 Evaluation of erosion-corrosion in multiphase flow via CFD and experimental analysis Wear 255 237-45

[41] Souza V A D and Neville A 2005 Corrosion and synergy in a WC-Co-Cr HVOF thermal spray coating-understanding their role in erosion-corrosion degradation Wear 259 171-80

[42] Bello J O et al 2007 Synergistic effects of micro-abrasion-corrosion of UNS S30403, S31603 and S32760 stainless steels Wear doi:10.1016/j.wear.2006.12.044

[43] Thakare M R, Wharton J A, Wood R J K and Menger C 2007 Exposure effects of alkaline drilling fluid on the microscale abrasion-corrosion of WC-based hardmetals Wear doi:10.1016/j.wear.2006.12.047

[44] Scrivani A, Ianelli S, Rossi A, Groppetti R, Casadei F and Rizzi G 2001 A contribution to the surface analysis and characterisation of HVOF coatings for petrochemical application Wear 250 107-13

[45] Wheeler D W and Wood R J K 1999 Erosion testing of diamond-coated choke valves Report No 98/EC221 Mechanical Engineering Consultancy Service, School of Engineering Sciences, University of Southampton

[46] Wheeler D W and Wood R J K 1999 Erosive wear behaviour of thick CVD diamond coatings Wear 225-229 523-36

[47] Wheeler D W and Wood R J K 1999 Solid particle erosion of CVD diamond coatings Wear 233-235 306-18

[48] Toma D, Brandl W and Marginean G 2001 Wear and corrosion behaviour of thermally sprayed cermet coatings Surf. Coat. Technol. 138 149-58

[49] Souza V A D and Neville A 2003 Linking electrochemical corrosion behaviour and corrosion mechanisms of thermal spray cermet coatings ( $\mathrm{WC}-\mathrm{CrNi}$ and $\mathrm{WC} / \mathrm{CrC}-\mathrm{CoCr}$ ) Mater. Sci. Eng. A 352 202-11

[50] Bjordal M, Bardal E, Rogne T and Eggen T G 1995 Erosion and corrosion properties of WC coatings and duplex stainless steel in sand-containing synthetic sea-water Wear 186-187 508-14

[51] Valentinelli L, Valente T, Casadei F and Fedrizzi L 2004 Mechanical and tribo-corrosion properties of $\mathrm{HVOF}$ sprayed WC-Co coatings Corros. Eng. Sci. Technol. 39 301-7

[52] Fedrizzi L, Valentinelli L, Rossi S and Segna S 2007 Tribocorrosion behaviour of HVOF cermet coatings Corros. Sci. 49 2781-99

[53] Wood R J K and Speyer A J 2004 Erosion-corrosion of candidate HVOF aluminium-based marine coatings Wear 256 545-56

[54] Barik R C, Wharton J A, Wood R J K, Tan K S and Stokes K R 2005 Erosion and erosion-corrosion performance of cast and thermally sprayed nickel-aluminium bronze Wear 259 230-42

[55] Berget J, Rogne T and Bardal E 2007 Erosion-corrosion properties of different $\mathrm{WC}-\mathrm{Co}-\mathrm{Cr}$ coatings deposited by the HVOF process - influence of metallic matrix composition and spray powder size distribution Surf. Coat. Technol. 201 7619-25

[56] Berget J, Bardal E and Rogne T 1998 Effects of powder composition on the erosion, corrosion and erosion-corrosion properties of HVOF sprayed WC based coatings Proc. 15th Int. Thermal Spray Conf., Thermal Spray, Vols 1 and 2-Meeting the Challenges of the 21st Century (Nice, France) vol 1 pp 305-12

[57] Al-Fadhli H Y, Stokes J, Hashmi M S J and Yilbas B S 2006 The erosion-corrosion behaviour of high velocity oxy-fuel (HVOF) thermally sprayed inconel-625 coatings on different metallic surfaces Surf. Coat. Technol. $2005782-8$

[58] Liu Z, Cabrero J, Niang S and Al Taha Z T 2007 Improving corrosion and wear performance of HVOF-sprayed
Inconel 625 and WC-Inconel 625 coatings by high power diode laser treatments Surf. Coat. Technol. 201 7149-58

[59] Cho J E, Hwang S Y and Kim K Y 2006 Corrosion behavior of thermal sprayed WC cermet coatings having various metallic binders in strong acidic environment Surf. Coat. Technol. 200 2653-62

[60] Basak A K, Matteazzi P, Vardavoulias M and Celis J-P 2006 Corrosion-wear behaviour of thermal sprayed nanostructured $\mathrm{FeCu} / \mathrm{WC}-\mathrm{Co}$ coatings Wear 261 1042-50

[61] Tan K S, Wharton J A and Wood R J K 2005 Solid particle erosion-corrosion behaviour of a novel HVOF nickel aluminium bronze coating for marine applications correlation between mass loss and electrochemical measurements Wear 258 629-40

[62] Wood R J K, Wharton J A, Speyer A J and Tan K S 2002 Investigation of erosion-corrosion processes using electrochemical noise measurements Tribol. Int. 35 631-41

[63] Stack M M and Abd El Badia T M 2006 On the construction of erosion-corrosion maps for WC/Co-Cr-based coatings in aqueous conditions Wear 261 1181-90

[64] Purandare Y P, Stack M M and Hovsepian P E 2006 Velocity effects on erosion-corrosion of $\mathrm{CrN} / \mathrm{NbN}$ 'superlattice' PVD coatings Surf. Coat. Technol. 201 361-70

[65] Gant A J et al 2004 The evaluation of tribo-corrosion synergy for WC-Co hardmetals in low stress abrasion Wear 256 500-16

[66] Shipway P H and Howell L 2005 Microscale abrasion-corrosion behaviour of WC-Co hardmetals and HVOF sprayed coatings Wear 258 303-12

[67] Thakare M R, Wharton J A, Wood R J K and Menger C 2007 Exposure effects of strong alkaline conditions on the microscale abrasion-corrosion of D-gun sprayed WC-10Co-4Cr coating Hyderabad Conf. Tribocorrosion (Hyderabad, India) Tribol. Int. Tribocorros. at press (special issue)

[68] Giroud A, Jouanny C, Heuze J L, Gaillard F and Guiraldenq P 1998 Friction and corrosion behavior of different ceramic coatings (oxides) obtained by thermal spray for qualification tests in sea water Proc. 15th Int. Thermal Spray Conf., Thermal Spray, Vols 1 and 2-Meeting the Challenges of the 21st Century (Nice, France) pp 211-16

[69] Bulloch J H and Callagy A G 1999 An in situ wear-corrosion study on a series of protective coatings in large induced draft fans Wear 235 284-92

[70] Knuuttila, Ahmaniemi S and Mantyla T 1999 Wet abrasion and slurry erosion resistance of thermally sprayed oxide coatings Wear 232 207-12

[71] Chang J T, Yeh C H, He J L and Chen K C 2003 Cavitation erosion and corrosion behavior of $\mathrm{Ni}-\mathrm{Al}$ intermetallic coatings Wear 255 162-9

[72] Chernega S M, Loskutova T V and Yantsevych K V 2003 Influence of corrosion component on the process of a cavitation-corrosive-wear of complex carbide coatings on a base of a chromium Metallofiz. Noveish. Tekhnol. 25 519-32

[73] Barik R C, Wharton J A, Wood R J K, Stokes K R and Jones R L 2005 Corrosion, erosion and erosion-corrosion performance of plasma electrolytic oxidation (PEO) deposited A1203 coatings Surf. Coat. Technol. 199 158-67

[74] Nie X, Meletis E I, Jiang J C, Leyland A, Yerokhin A L and Matthews A 2002 Abrasive wear/corrosion properties and TEM analysis of $\mathrm{Al}_{2} \mathrm{O}_{3}$ coatings fabricated using plasma electrolysis Surf. Coat. Technol. 149 245-51

[75] Ferreira S C et al 2006 Tribocorrosion behaviour of $\mathrm{ZrOxNy}$ thin films for decorative applications Surf. Coat. Technol. $2006624-39$

[76] de Damborenea J, Navas C, García J A, Arenas M A and Conde A 2007 Corrosion-erosion of TiN-PVD coatings in collagen and cellulose meat casing Surf. Coat. Technol. 201 5751-7 
[77] Quan Z, Wu P-Q, Tang L and Celis J-P 2006 Corrosion-wear monitoring of TiN coated AISI 316 stainless steel by electrochemical noise measurements Appl. Surf. Sci. 253 1194-7

[78] Dahm K L and Dearnley P A 2005 Abrasion response and abrasion-corrosion interactions for a coated biomedical stainless steel Wear 259 933-42

[79] Holleck H and Schier V 1995 Multilayer PVD coatings for wear protection Surf. Coat. Technol. 76-77 328-36

[80] Rossi S, Fedrizzi L, Leoni M, Scardi P and Massiani Y 1999 (Ti,Cr)N and Ti/TiN PVD coatings on 304 stainless steel substrates: wear-corrosion behaviour Thin Solid Films 350 161-7

[81] Galliano F, Galvanetto E, Mischler S and Landolt D 2001 Tribocorrosion behaviour of plasma nitrided Ti-6Al-4V alloy in neutral $\mathrm{NaCl}$ solution Surf. Coat. Technol. $145121-31$

[82] Fernandes A C, Vaz F, Ariza E, Rocha L A, Ribeiro A R L, Vieira A C, Rivière J P and Pichon L 2006 Tribocorrosion behaviour of plasma nitrided and plasma nitrided + oxidised Ti6Al4V alloy Surf. Coat. Technol. 200 6218-24

[83] Wang C-J and Jaw J-H 2004 Study of wear behavior of nitride layers in Fe-Mn-Al-C alloys Surf. Coat. Technol. 177-178 477-82

[84] Neville A, Reza F, Chiovelli S and Revega T 2006 Assessing metal matrix composites for corrosion and erosion-corrosion applications in the oil sands industry Corrosion 62 657-75

[85] Reyes M and Neville A 2003 Degradation mechanisms of Co-based alloy and WC metal-matrix composites for drilling tools offshore Wear 255 1143-56

[86] Tucker R C 1998 An overview of alternative coatings for wear and corrosion resistance Proc. 15th Int. Thermal Spray Conf., Thermal Spray, Vols 1 and 2-Meeting the Challenges of the 21st Centuary (Nice, France) pp 103-9

[87] Lekka M, Kouloumbi N, Gajo M and Bonora P L 2005 Corrosion and wear resistant electrodeposited composite coatings Electrochim. Acta 50 4551-6

[88] Benea L, Bonora P L, Borello A and Martelli S 2001 Wear corrosion properties of nano-structured $\mathrm{SiC}$-nickel composite coatings obtained by electroplating Wear 249 995-1003

[89] Wang L, Zhang J, Zeng Z, Hu L and Xue Q 2006 Fabrication of a nanocrystalline $\mathrm{Ni}-\mathrm{Co} / \mathrm{CoO}$ functionally graded layer with excellent electrochemical corrosion and tribological performance Nanotechnology 17 1-10

[90] Fedrizzi L, Rossi S, Bellei F and Deflorian F 2002 Wear-corrosion mechanism of hard chromium coatings Wear 253 1173-81

[91] Andersson P and Blomberg A 1994 Instability in the tribochemical wear of silicon-carbide in unlubricated sliding contacts Wear 174 1-7

[92] Wilson S and Alpas A T 2000 Tribo-layer formation during sliding wear of TiN coatings Wear $245223-9$

[93] Fateh N, Fontalvo G A, Gassner G and Mitterer C 2007 Influence of high-temperature oxide formation on the tribological behaviour of TiN and VN coatings Wear 262 1152-8

[94] Kostornov A G, Panasyuk A D, Podchernyaeva I A, Umanskii A P and Kostenko A D 2003 Composite ceramic materials and coatings for tribological use Powder Metall. Met. Ceram. 42 249-56

[95] Niebuhr T, Bubert H, Steffens H-D, Haumann D, Kauder K and Dämgen U 1997 Examination of wear mechanisms of hard coatings Fresenius' J. Anal. Chem. 358 278-80

[96] Suszko T, Gulbinski W and Jagielski J 2005 The role of surface oxidation in friction processes on molybdenum nitride thin films Surf. Coat. Technol. 194 319-24

[97] Ouyang J H and Sasaki S 2004 Tribo-oxidation of cathodic arc ion-plated $(\mathrm{V}, \mathrm{Ti}) \mathrm{N}$ coatings sliding against a steel ball under both unlubricated and boundary-lubricated conditions Surf. Coat. Technol. 187 343-57

[98] Wu P Q, Drees D, Stals L and Celis J P 1999 Comparison of wear and corrosion wear of TiN coatings under uni- and bidirectional sliding Surf. Coat. Technol. 113 251-8

[99] Wang B Q and Luer K 1994 The erosion-oxidation behavior of $\mathrm{HVOF} \mathrm{Cr}_{3} \mathrm{C}_{2}-\mathrm{NiCr}$ cermet coating Wear 174 177-85

[100] Lambrechts P, Goovaerts K, Bharadwaj D, De Munck J, Bergmans L, Peumans M and Van Meerbeek B 2006 Degradation of tooth structure and restorative materials: a review Wear 261 980-6

[101] Nagarajan V S, Jahanmir S and Thompson V P 2004 In vitro contact wear of dental composites Dent. Mater. 20 63-71

[102] Nagarajan V S, Hockey B J, Jahanmir S and Thompson V P 2000 Contact wear mechanisms of a dental composite with high filler content J. Mater. Sci. 35 487-96

[103] Lewis R and Dwyer-Joyce R S 2005 Wear of human teeth: a tribological perspective Proc. Inst. Mech. Eng. J.—J. Eng. $2191-18$ 